Sharif University of Technology
Scientia Iranica
Transactions E: Industrial Engineering
IRA IENTIA $\quad$\begin{tabular}{l} 
h / scientiairanica.sharif.edu \\
\hline
\end{tabular}

\title{
Evaluation of supply chain of a shipping company in Iran by a fuzzy relational network data envelopment analysis model
}

\author{
H. Omrani ${ }^{a}, *$, M. Keshavarz ${ }^{a}$, and S.F. Ghaderi ${ }^{b}$ \\ a. Faculty of Industrial Engineering, Urmia University of Technology, Urmia, P.O. Box 57155-419, Iran. \\ b. School of Industrial Engineering and Research Institute of Energy Management and Planning, College of Engineering, University \\ of Tehran, Tehran, P.O. Box 515-14395, Iran.
}

Received 1 March 2016; received in revised form 11 November 2016; accepted 31 December 2016

KEYWORDS
Relational network
DEA;
Supply chain;
Fuzzy data;
Efficiency;
Two-level
mathematical
program.

\section{KEYWORDS}

DEA;

Supply chain;

Fuzzy data;

program.

\begin{abstract}
The existing relational network Data Envelopment Analysis (DEA) models evaluate the performance of Decision Making Units (DMUs) with precise data. Whereas, in the real-world applications, there are many Supply Chain (SC) networks with imprecise and vague figures. This paper develops a relational network DEA model for evaluating the performance of supply chains with fuzzy numbers. The proposed fuzzy model is capable of evaluating the performance of all kinds of network structures. A pair of twolevel mathematical programs is utilized to convert the fuzzy relational network DEA to a conventional crisp one. For this purpose, the upper and lower bounds of the efficiencies are calculated by $\alpha$-cut concept. The proposed model is implemented using actual data from the supply chain of an international shipping company in Iran.
\end{abstract}

(C) 2018 Sharif University of Technology. All rights reserved.

\section{Introduction}

Under the blows of globalization and piercing of technology through various corners and places of the world, the competition amongst different companies, manufacturers, and traders is getting tougher and harder day by day. Nowadays, it is very well understood that for the companies to compete, their supply chain must be competitive. This has made the management of supply chain a very important and crucial subject for successfully running the companies. Consequently,

\footnotetext{
*. Corresponding author. Tel.: +984413554180,

Fax: +984413554184

E-mail addresses: h.omrani@uut.ac.ir (H. Omrani);

mehdi.keshavarz@ine.uut.ac.ir (M. Keshavarz);

ghaderi@ut.ac.ir (S.F. Ghaderi)
}

many researches and studies are being conducted for defining proper and effective methods of Supply Chain Management (SCM) and measuring their efficiency.

According to Deloitte Consulting [1] report, which has been published after studying and surveying more than 200 outsized producers and distributors in the United States and Canada (including automobile, aerospace, consumable items, high-tech industries, etc.), "no longer will companies compete against other companies, but total supply chains will compete against other supply chains." Companies do not compete with each other any longer as independent individuals with exclusive brands, but rather as integral parts of their supply chains. For example, in mobile competition, Microsoft (software supplier) and HTC (device manufacturer) can be mentioned, which establish a supply chain competition with the similar chain of Symbian (software supplier) and Nokia 
(device manufacturer) [2]. Similar examples can be given in other industries such as household appliances and electronic devices, e.g. Bosch, Sony, Samsung, LG, etc.

The supply chain may also be defined as a network of associated and interdependent organizations reciprocally and cooperatively working together to handle, regulate, monitor, and improve the flows of resources and information from first producers to end consumers [3].

The lack of harmony and coordination among various parts and departments within a supply chain will result in damages and financial losses. Here comes the importance of continuous evaluation of supply chain within an organization and its key role in ongoing improvements as well as in detection and treatment of loose links for final success and achieving the organizational goals.

In previous studies under traditional DEA, supply chains were being treated like a black box (without considering the internal processes), and evaluation focused on a specific member of the supply chain, individually, such as distributors' performance [4], purchasers' performance [5], vendors' performance [6], etc. In this paper, contrary to the previous studies on evaluation of supply chain performance with DEA, the processes are evaluated in combination and mutual interactions using Relational Network DEA.

The inputs and outputs of relational network DEA presented by Kao and Hwang [7] are precise and crisp, whereas, in the real-world applications, many data in supply chains are imprecise. The example taken in this paper is a shipping company, which, in view of its nature of bulky operations, very wide and international field of coverage, difficulty in harmonized and identical data gathering, human error, and lack of unified measurement systems in various ports and places of the world, may result in imprecise data. One of the methods used to resolve such difficulties and overcome the problem of imprecise data is application of fuzzy method. Kao and Liu [8] developed a two-stage model of relational DEA with fuzzy data in which the two stages were connected in series. Although their model was useful, it had some drawbacks. Firstly, their proposed model was non-linear for lower bound of the efficiency calculation. Nonlinear programming models are not as popular as linear ones and can suggest the local optimum solutions. Therefore, Kao and Liu [8] suggested developing their model to a linear one as a direction for future research. Secondly, they calculated the efficiency of processes in lower bound by utilizing the optimal variables obtained from the non-linear model. Non-linear model suggests local optimum solution; therefore, the values of decision making variables are local, too. The local decision making variables also mean that the efficiencies of the processes are local. Thirdly, they presented their model for a system in which two stages were connected in series. While, in the real world, most systems are not in two stages. Recently, Kao and Lin [9] developed relational DEA model for calculating the efficiency of parallel systems with fuzzy numbers. Whereas, most network systems in the real world are not simple parallel systems and they are mixtures of series and parallel structures. Therefore, they suggested as future direction to expand the relational network DEA for networks systems with fuzzy numbers.

In this paper, a new fuzzy relational network DEA model will be proposed to address these shortfalls in the literature. In summary, our model has some advantages. Firstly, the proposed model can suggest general series systems and all kinds of network structures. Secondly, both upper and lower bounds of the proposed model are linear. Thirdly, the upper and lower bounds are obtained from linear model. Therefore, the efficiencies of processes obtained from decisive variables are global. Fourthly, supply chains usually consist of a number of sub-systems; therefore, the proposed model is very suitable for all kinds of supply chains.

In order to explain the model in practice and actuality, a case study has been established using a well-known shipping line with extensive networks and international supply chain. The supply chain of the mentioned shipping line consists of multinational suppliers, manufacturers, and distributors. In addition, this paper is the first paper which develops the relational network DEA with fuzzy method. Besides, the case study of this paper is novel and has not been investigated in the previous studies.

The rest of the paper is organized as follows. The next section provides literature review on network DEA model and efficiency studies on transportation. In Section 3 , the relational model for a general series system in deterministic situation is shown. In Section 4, fuzzy relational DEA for general series system is presented. In Section 5, the relational model for supply chain of shipping firm in deterministic situation is presented and the model is developed for measuring the efficiency of network of supply chain. In Section 6, a case of shipping company in Iran with fuzzy data is used to explain the network fuzzy relational model and, finally, conclusion is presented in Section 7 .

\section{Literature review}

\subsection{Network DEA model}

DEA was initially introduced by Charnes et al. [10] and is a non-parametric method for analyzing and evaluating the relative efficiency of similar DMUs based on multiple inputs and outputs.

No assumptions are made regarding the processes 
occurring inside a DMU in DEA. On the other hand, DEA considers a DMU as "black box," which takes the first inputs to create the final output without surveying the internal processes [11].

There are various methods for evaluating the performance of supply chain, among which DEA has mostly been utilized in academic studies. DEA is a suitable means for measuring the performance of the supply chain, because it deals with multiple inputs and outputs. Besides, it does not require prior unrealistic assumptions for variables, which are virtually existent in optimization supply chain models such as rate of demand, leads time, etc.

Most of the studies on supply chain evaluation with DEA were confined to surveying the supply chain members individually or as a "black box." Whereas, the supply chains usually involve two or more stages, in which the output of one stage is the input of the next one. Thus, it cannot be treated as a black box. Also, these stages are very much interconnected and related to each other. Consider a supply chain with two stages in which the manufacturer is at the first stage and the retailer is at the second stage. In this system, if the retailer achieves maximum efficiency in conflict with the manufacturer, it is reasonable that the manufacturer would try to increase its outputs in order to achieve maximum efficiency. However, a surge in the manufacturer's outputs causes a build-up in the retailer's inputs, because the outputs of the first stage are the inputs of second stage. Such issues cannot be tackled by the classical DEA models.

The problems and deficiencies associated with classical DEA system led researchers to focus more concentration and studies on the internal processes and structure of DMUs. Kao and Hwang [7] classified the researches into three groups of "independent," "connected," and "relational" methodology.

In the independent methodology, the efficiencies of the system and sub-processes are calculated independently in which there is no relationship between the two mentioned efficiencies. This methodology is used in [12-14]. These models were first studied by Seiford and Zhu [12]. They utilized this methodology to evaluate the efficiency of the top commercial banks in the United States. A similar model was studied by Sexton and Lewis [13] in order to measure the efficiency of the teams of Major League Baseball.

In the connected methodology, for measuring efficiency of the system, the interactions between the two processes are also considered. Then, after system efficiency is obtained using the above-mentioned method, like in the independent methodology, the efficiencies of the two processes are worked out separately and independently. In this methodology, although the calculated efficiency is closer to the factuality of the system, again, there is no direct relationship between the system and process efficiencies. This approach was introduced by the network DEA model of Färe and Grosskopf [15].

In the relational methodology, a single mathematical program is used to calculate the system and process efficiencies, and through the constraints of the mathematical program, the relationship between the system efficiency and process efficiency is obtained.

The relational approach and methodology was first introduced by Kao and Hwang [16] for evaluation of a system which had two sub-processes connected in series. Then, Kao [17] further expended the above-mentioned two-stage model by adding more subprocesses in series and in parallel. They used their model as a case study for evaluating the efficiency of non-life insurance firms in Taiwan. Kao and Hwang [7] developed this model for evaluation of all types of network structures. Kao [18] developed a relational DEA model for measuring the efficiency of a dynamic system. Relational DEA was studied in several industries, such as high-tech industries [19], banks [20], and hotels [21]. Hsieh and Lin [21] evaluated the efficiencies of Touristic hotels in Taiwan by utilizing Kao's [17] model. Chen and Yan [22] used the network DEA to evaluate efficiency of a supply chain consisting of one supplier and two manufacturers in three approaches of centralized, decentralized, and mixed. Toloo et al. [23] presented a new relational linear DEA model for measuring the efficiency of two-stage processes with shared inputs. They applied this model in banking industry and university operations.

The inputs and outputs of the mentioned relational network DEA are precise and constant, whereas the inputs and outputs in the real world are sometimes imprecise and vague. The vague values could be initiated due to non-quantifiable, incomplete, and non-obtainable information [24]. Imprecise or vague data are usually expressed with fuzzy numbers, bound intervals, and ordinal (rank order) data. Fuzzy sets, which were introduced by Zadeh [25], are one of the common methods for solving DEA with imprecise data. The applications of fuzzy set theory in DEA are usually divided into four categories [24,26]: tolerance approach [27,28], $\alpha$-level based approach [29,30], fuzzy ranking approach [31,32], and possibility approach [33,34].

The number of studies on the relational network DEA with fuzzy number is very limited. Kao and Liu [8] expanded the Kao and Hwang [16] model with fuzzy numbers, which was based on two sub-processes connected in series. Kao and Lin [9] extended this model for parallel systems with fuzzy numbers. Lozano and Moreno [35] presented a new approach to compute the efficiency of the relational network DEA model in two-stage systems with fuzzy data. 
This paper is designed to develop a relational network DEA methodology applicable to all types of network structures and processes with fuzzy numbers. It uses a supply chain network of a shipping line to examine the developed model.

\subsection{Relative efficiency studies in transportation}

A review of the studies conducted in transportation industry reveals that there have been extensive DEA models for railway [36,37], airline industries [38], public transportation [39], airports [40], and sea ports [41,42]. Markovits-Somogyi [43] reviewed the DEA studies to date in the transportation industry and showed that out of the 64 transport studies using DEA, the majority were on airports and seaports (23 and 21 respectively), followed by public transport (10), railways (9), airlines (4), and others (2), while the studies on marine transportation were restricted to sea ports only. According to published data, the number of studies conducted on the shipping industry is very limited [44,45]. Recently, Panayides et al. [45] evaluated the operational and market efficiency of 26 major shipping companies including 15 container lines, 6 dry bulk companies, and 5 tanker firms by utilizing both SFA and DEA. Bang et al. [44] evaluated the relative efficiency of liner shipping companies in terms of operational and financial performance, and further examined the effect of strategic and operational management on efficiency performance.

\section{Relational DEA}

The conventional DEA model was proposed by Charnes et al. [10]. Let $X_{i j}, i=1, \cdots, m$ and $Y_{r j}, r=1, \cdots, s$ denote the $i$ th input and $r$ th output, respectively, of the $j$ th DMU, $j=1, \cdots, n$. The relative efficiency of DMU $k$ under an assumption of constant returns to scale $(\mathrm{CCR})$ is calculated via the following DEA model [10]:

$$
\begin{aligned}
& E_{k}=\max \sum_{r=1}^{s} u_{r} Y_{r k}, \\
& \text { s.t. } \\
& \sum_{i=1}^{m} v_{i} X_{i k}=1, \\
& \sum_{r=1}^{s} u_{r} Y_{r j}-\sum_{i=1}^{m} v_{i} X_{i j} \leq 0, \quad j=1, \cdots, n, \\
& \quad u_{r}, v_{i} \geq \varepsilon, \quad r=1, \cdots, s, \quad i=1, \cdots, m,
\end{aligned}
$$

where $E_{k}$ is the efficiency of DMU $k, v_{i}$ and $u_{r}$ are the virtual multipliers associated with the $i$ th input and $r$ th output, respectively, and $\varepsilon$ is a small non-
Archimedean number [46]. Model (1) is commonly denoted by the ratio-form DEA model because the constraint $\sum_{r=1}^{s} u_{r} Y_{r j}-\sum_{i=1}^{m} v_{i} X_{i j} \leq 0$ has a ratio form of $\sum_{r=1}^{s} u_{r} Y_{r j} / \sum_{i=1}^{m} v_{i} X_{i j} \leq 1$, which is just efficiency of DMU $k$ for $j=k$. The dual form of Model (1) is as follows:

$$
E_{k}=\min \theta-\varepsilon\left(\sum_{i=1}^{m} s_{i}^{x}+\sum_{r=1}^{s} s_{r}^{y}\right),
$$

s.t.

$$
\begin{array}{cc}
\sum_{j=1}^{n} \lambda_{j} x_{i j}-s_{i}^{x}=\theta x_{i k}, & i=1, \cdots, m, \\
\sum_{j=1}^{n} \lambda_{j} y_{r j}-s_{r}^{y}=y_{r k}, & r=1, \cdots, s, \\
\lambda_{j}, s_{i}^{x}, s_{r}^{y} \geq 0, & j=1, \cdots, n, \\
r=1, \cdots, s, & i=1, \cdots, m .
\end{array}
$$

Model (2) is usually referred to as envelopment-form DEA model, because the production possibility set is enveloped by $\sum_{j=1}^{n} \lambda_{j} x_{i j} \leq \theta x_{i k}, \sum_{j=1}^{n} \lambda_{j} y_{r j} \leq y_{r k}$ and $\lambda_{j} \geq 0$.

Kao and Hwang [16] introduced a relational DEA model to calculate the efficiency of a two-stage production process where the outputs of the first stage were the inputs of the second stage. Kao [17] extended the Kao and Hwang [16] model to general series system by adding more stages in the series structure. The general series system of Kao [17] has the structure shown in Figure 1, where $h$ processes are connected by intermediate products. For consistency, the notation in Kao [17] will be used as far as possible:

$X_{i j} \quad$ Amount of the $i$ th exogenous input, $i=1, \cdots, m$, consumed by DMU $j$, $j=1, \ldots, n$;

$Y_{r j} \quad$ Amount of the $r$ th final output, $r=1, \cdots, s$, produced by DMU $j$;

$Z_{p j}^{(t)} \quad$ Amount of the $p$ th intermediate product, $p=1, \cdots, q$, of process $t$, $t=1, \cdots, h-1$, for $\mathrm{DMU} j$;

$v_{i} \quad$ Multiplier for the $i$ th input;

$u_{r} \quad$ Multiplier for the $r$ th output;

$w_{p}^{(t)} \quad$ Multiplier for the $p$ th intermediate product of process $t$.

Kao [17] proposed the following relational DEA approach for general series system:

$$
E_{k}=\max \sum_{r=1}^{s} u_{r} Y_{r k},
$$




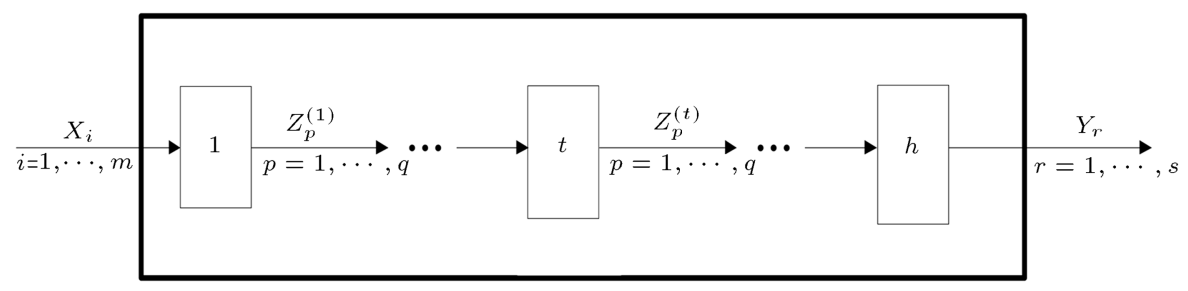

Figure 1. The series system discussed in Kao [17].

s.t.

$$
\begin{aligned}
& \sum_{i=1}^{m} v_{i} X_{i k}=1 \\
& \sum_{r=1}^{s} u_{r} Y_{r j}-\sum_{i=1}^{m} v_{i} X_{i j} \leq 0, \quad j=1, \cdots, n, \\
& \sum_{p=1}^{q} w_{p}^{(1)} Z_{p j}^{(1)}-\sum_{i=1}^{m} v_{i} X_{i j} \leq 0, \quad j=1, \cdots, n, \\
& \sum_{p=1}^{q} w_{p}^{(t)} Z_{p j}^{(t)}-\sum_{p=1}^{q} w_{p}^{(t-1)} Z_{p j}^{(t-1)} \leq 0 \\
& j=1, \cdots, n, \quad t=2, \cdots, h-1, \\
& \sum_{r=1}^{s} u_{r} Y_{r j}-\sum_{p=1}^{q} w_{p}^{(h-1)} Z_{p j}^{(h-1)} \leq 0 \\
& j=1, \cdots, n, \\
& u_{r}, v_{i}, w_{p}^{(t)} \geq \varepsilon, \quad r=1, \cdots, s, \\
& i=1, \cdots, m, \quad p=1, \cdots, q, \\
& t=1, \cdots, h-1 \text {. }
\end{aligned}
$$

Let $v_{i}^{*}, u_{r}^{*}$, and $w_{p}^{*(t)}$ be the optimal multipliers obtained from Model (3). The efficiency of each process for DMU $k$ is calculated as:

$$
\begin{aligned}
E_{k} & =\sum_{r=1}^{s} u_{r}^{*} Y_{r k} / \sum_{i=1}^{m} v_{i}^{*} X_{i k}, \\
E_{k}^{1} & =\sum_{p=1}^{q} w_{p}^{*(1)} Z_{p k}^{(1)} / \sum_{i=1}^{m} v_{i}^{*} X_{i k}, \\
E_{k}^{t} & =\sum_{p=1}^{q} w_{p}^{*(t)} Z_{p k}^{(t)} / \sum_{p=1}^{q} w_{p}^{*(t-1)} Z_{p k}^{(t-1)} \\
t & =2, \cdots, h-1, \\
E_{k}^{h} & =\sum_{r=1}^{s} u_{r}^{*} Y_{r k} / \sum_{p=1}^{q} w_{p}^{*(h-1)} Z_{p k}^{(h-1)},
\end{aligned}
$$

where $E_{k}$ is the system efficiency and $E_{k}^{(t)}$ is the processes efficiencies.

\section{Fuzzy relational DEA for general series}

The inputs and outputs of the relational DEA for series structure models are crisp numbers; however, in many real-world applications, the data are inexact. This section extends the Kao and Liu (2011) [8] fuzzy twostage NDEA approach for general series structures. Therefore, first, a general procedure for finding the upper and lower bounds of all kinds of series structure will be presented and, then, the procedure is applied to general series system of Kao [17].

\subsection{Upper bound}

The procedure for calculating the upper bound efficiency of series structure may be summarized as follows:

- Step 1: Write relational DEA (with maximum objective direction) of any system using the methodology of Kao and Hwang [7];

- Step 2: Assume that each variable varies between upper and lower bounds and define the $\alpha$-cuts of variables. By this assumption, the upper bound can be expressed as follows:

$$
\begin{aligned}
\left(E_{k}\right)_{\alpha}^{U}= & \max \left(X_{i j}^{t}\right)_{\alpha}^{L} \leq x_{i j}^{t} \leq\left(X_{i j}^{t}\right)_{\alpha}^{U} \\
& \left(Z_{h j}^{t}\right)_{\alpha}^{L} \leq z_{h j}^{t} \leq\left(Z_{h j}^{t}\right)_{\alpha}^{U}(x, z, y), \\
& \left(Y_{r j}^{t}\right)_{\alpha}^{L} \leq y_{r j}^{t} \leq\left(Y_{r j}^{t}\right)_{\alpha}^{U} \\
& \forall i, h, j, t, r
\end{aligned}
$$

where $E_{k}(x, y, z)$ is defined in Step 1 and $x, z$, and $y$ represent the inputs, intermediates, and outputs of any system. Note that the dimension of variables in Model (5) depends on the system;

- Step 3: Model (5) is a two-level mathematical program. Therefore, for converting it to one-level mathematical program, adjust the parameters in Model (5) as follows:

3.1. Substitute the largest value of all outputs and smallest value of all inputs with DMU $k$ (index of specific DMU being assessed) in the model; 
3.2. Substitute the smallest value of all outputs and largest value of all inputs with the other DMU in the model;

3.3. Add the constraints of intermediate products (each intermediate product is between its upper and lower bounds) to the model.

- Step 4: Convert the model to a linear one by substituting the nonlinear terms with another variables and, then, update the bounded constraints.

\subsection{Lower bound}

The procedure for calculating the lower bound efficiency of network structure is summarized as follows:

- Step 1: Write the dual model of Step 1 (with minimum objective direction);

- Step 2: Using the $\alpha$-cuts introduced in Step 2 of upper bound, express the lower bound as:

$$
\begin{aligned}
\left(E_{k}\right)_{\alpha}^{L}= & \min \left(X_{i j}^{t}\right)_{\alpha}^{L} \leq x_{i j}^{t} \leq\left(X_{i j}^{t}\right)_{\alpha}^{U} E_{k}(x, z, y) \\
& \left(Z_{h j}^{t}\right)_{\alpha}^{L} \leq z_{h j}^{t} \leq\left(Z_{h j}^{t}\right)_{\alpha}^{U} \\
& \left(Y_{r j}^{t}\right)_{\alpha}^{L} \leq y_{r j}^{t} \leq\left(Y_{r j}^{t}\right)_{\alpha}^{U} \\
& \forall i, h, j, t, r
\end{aligned}
$$

where $E_{k}(x, y, z)$ is defined in Step 1 of lower bound and $x, z$, and $y$ represent the inputs, intermediates, and outputs of any system;

- Step 3: Adjust the parameters as follows in Model (6):

3.1. Substitute the smallest value of all outputs and largest value of all inputs with DMU $k$ in the model;

3.2. Substitute the largest value of all outputs and smallest value of all inputs with the other DMU in the model;

3.3. Add the constraints of intermediate products (each intermediate product is between its upper and lower bounds) to the model.

- Step 4: Convert the model to a linear one by substituting the nonlinear terms with another variables and, then, update the bounded constraints.

\subsection{Series structure}

This subsection develops the Kao [17] relational DEA for series structure with fuzzy data by using the procedure introduced in Subsections 4.1 and 4.2.

\subsubsection{Upper bound}

For finding the upper bound, the procedure introduced in Subsection 5.1 is used as follows:

- Step 1: Model (3) is the relational DEA model of general series system;
- Step 2: Denote $\left(X_{i j}\right)_{\alpha}=\left[\left(X_{i j}\right)_{\alpha}^{L},\left(X_{i j}\right)_{\alpha}^{U}\right],\left(Z_{p j}^{t}\right)_{\alpha}=$ $\left[\left(Z_{p j}^{t}\right)_{\alpha}^{L},\left(Z_{p j}^{t}\right)_{\alpha}^{U}\right]$ and $\left(Y_{r j}\right)_{\alpha}=\left[\left(Y_{r j}\right)_{\alpha}^{L},\left(Y_{r j}\right)_{\alpha}^{U}\right]$ as the $\alpha$-cuts of variables. By this assumption, the upper bound can be expressed as:

$$
\begin{aligned}
\left(E_{k}\right)_{\alpha}^{U}= & \max \left(X_{i j}^{t}\right)_{\alpha}^{L} \leq x_{i j}^{t} \leq\left(X_{i j}^{t}\right)_{\alpha}^{U} E_{k}(x, z, y) \\
& \left(Z_{h j}^{t}\right)_{\alpha}^{L} \leq z_{h j}^{t} \leq\left(Z_{h j}^{t}\right)_{\alpha}^{U} \\
& \left(Y_{r j}^{t}\right)_{\alpha}^{L} \leq y_{r j}^{t} \leq\left(Y_{r j}^{t}\right)_{\alpha}^{U} \\
& \forall i, h, j, t, r
\end{aligned}
$$

where $E_{k}(x, y, z)$ is defined in Step 1 (Model (3));

- Step 3: Substitute the upper and lower values of inputs, outputs, and intermediate products by following Step 3 of Subsection 5.1. After the substitution, Model (7) changes as follows:

$$
\left(E_{k}\right)_{\alpha}^{U}=\max \sum_{r=1}^{s} u_{r}\left(Y_{r k}\right)_{\alpha}^{U}
$$

s.t.

$$
\sum_{i=1}^{m} v_{i}\left(X_{i k}\right)_{\alpha}^{L}=1
$$$$
\sum_{r=1}^{s} u_{r}\left(Y_{r k}\right)_{\alpha}^{U}-\sum_{i=1}^{m} v_{i}\left(X_{i k}\right)_{\alpha}^{L} \leq 0,
$$$$
\sum_{r=1}^{s} u_{r}\left(Y_{r j}\right)_{\alpha}^{L}-\sum_{i=1}^{m} v_{i}\left(X_{i j}\right)_{\alpha}^{U} \leq 0,
$$$$
j=1, \cdots, n, \quad j \neq k,
$$$$
\sum_{p=1}^{q} w_{p}^{(1)} z_{p k}^{(1)}-\sum_{i=1}^{m} v_{i}\left(X_{i k}\right)_{\alpha}^{L} \leq 0,
$$$$
\sum_{p=1}^{q} w_{p}^{(1)} z_{p j}^{(1)}-\sum_{i=1}^{m} v_{i}\left(X_{i j}\right)_{\alpha}^{U} \leq 0,
$$$$
j=1, \cdots, n, \quad j \neq k,
$$$$
\sum_{p=1}^{q} w_{p}^{(t)} z_{p j}^{(t)}-\sum_{p=1}^{q} w_{p}^{(t-1)} z_{p j}^{(t-1)} \leq 0
$$$$
j=1, \cdots, n, \quad t=2, \cdots, h-1,
$$$$
\sum_{r=1}^{s} u_{r}\left(Y_{r k}\right)_{\alpha}^{U}-\sum_{p=1}^{q} w_{p}^{(h-1)} z_{p k}^{(h-1)} \leq 0,
$$$$
\sum_{r=1}^{s} u_{r}\left(Y_{r j}\right)_{\alpha}^{L}-\sum_{p=1}^{q} w_{p}^{(h-1)} z_{p j}^{(h-1)}
$$

$$
j=1, \cdots, n, \quad j \neq k,
$$




$$
\begin{aligned}
& \left(Z_{p j}^{(t)}\right)_{\alpha}^{L} \leq z_{p j}^{(t)} \leq\left(Z_{p j}^{(t)}\right)_{\alpha}^{U}, \\
& u_{r}, v_{i}, w_{p}^{(t)} \geq \varepsilon, \quad r=1, \cdots, s, \\
& i=1, \cdots, m, \quad p=1, \cdots, q, \\
& t=1, \cdots, h-1 .
\end{aligned}
$$

- Step 4: Model (8) is nonlinear model terms of $w_{p}^{(t)} z_{p j}^{(t)}$. Therefore, to transform it into linear programming, assume:

$$
L_{p j}^{(t)}=w_{p}^{(t)} z_{p j}^{(t)}, \quad t=1, \cdots, h-1 .
$$

Substituting Model (9) into Model (8) and multiplying each term in constraint $\left(Z_{p j}^{(t)}\right)_{\alpha}^{L} \leq z_{p j}^{(t)} \leq\left(Z_{p j}^{(t)}\right)_{\alpha}^{U}$ by $w_{p}^{(t)}$, Model $(8)$ changes to a linear programming as follows:

$$
\left(E_{k}\right)_{\alpha}^{U}=\max \sum_{r=1}^{s} u_{r}\left(Y_{r k}\right)_{\alpha}^{U},
$$

s.t.

$$
\begin{aligned}
& \sum_{i=1}^{m} v_{i}\left(X_{i k}\right)_{\alpha}^{L}=1 \\
& \sum_{r=1}^{s} u_{r}\left(Y_{r k}\right)_{\alpha}^{U}-\sum_{i=1}^{m} v_{i}\left(X_{i k}\right)_{\alpha}^{L} \leq 0, \\
& \sum_{r=1}^{s} u_{r}\left(Y_{r j}\right)_{\alpha}^{L}-\sum_{i=1}^{m} v_{i}\left(X_{i j}\right)_{\alpha}^{U} \leq 0 \\
& j=1, \cdots, n, \quad j \neq k, \\
& \sum_{p=1}^{q} L_{p k}^{(1)}-\sum_{i=1}^{m} v_{i}\left(X_{i k}\right)_{\alpha}^{L} \leq 0 \\
& \sum_{p=1}^{q} L_{p j}^{(1)}-\sum_{i=1}^{m} v_{i}\left(X_{i j}\right)_{\alpha}^{U} \leq 0 \\
& j=1, \cdots, n, \quad j \neq k, \\
& \sum_{p=1}^{q} L_{p j}^{(t)}-\sum_{p=1} q L_{p j}^{(t-1)} \leq 0, \\
& j=1, \cdots, n, \quad t=2, \cdots, h-1, \\
& \sum_{r=1}^{s} u_{r}\left(Y_{r k}\right)_{\alpha}^{U}-\sum_{p=1}^{q} L_{p k}^{(h-1)} \leq 0 \\
& \sum_{r=1}^{s} u_{r}\left(Y_{r j}\right)_{\alpha}^{L}-\sum_{p=1}^{q} L_{p j}^{(h-1)} \leq 0,
\end{aligned}
$$

$$
\begin{gathered}
j=1, \cdots, n, \quad j \neq k, \\
w_{p}^{(t)}\left(Z_{p j}^{(t)}\right)_{\alpha}^{L} \leq L_{p j}^{(t)} \leq w_{p}^{(t)}\left(Z_{p j}^{(t)}\right)_{\alpha}^{U}, \\
t=1, \cdots, h-1, \\
u_{r}, v_{i}, w_{p}^{(t)} \geq \varepsilon, \quad r=1, \cdots, s, \\
i=1, \cdots, m, \quad p=1, \cdots, q \\
t=1, \cdots, h-1 .
\end{gathered}
$$

The optimum values of the decision variables achieved by Model (10) are used to calculate the efficiency of sub-processes as follows:

$$
\begin{aligned}
\left(E_{k}\right)_{\alpha}^{U} & =\sum_{r=1}^{s} u_{r}^{*}\left(Y_{r k}\right)_{\alpha}^{U} / \sum_{i=1}^{m} v_{i}^{*}\left(X_{i k}\right)_{\alpha}^{L}, \\
\left(E_{k}^{1}\right)_{\alpha}^{U} & =\sum_{p=1}^{q} L_{p k}^{*(1)} / \sum_{i=1}^{m} v_{i}^{*}\left(X_{i k}\right)_{\alpha}^{L}, \\
\left(E_{k}^{t}\right)_{\alpha}^{U} & =\sum_{p=1}^{q} L_{p k}^{*(t)} / \sum_{p=1}^{q} L_{p k}^{*(t-1)}, \quad t=2, \cdots, h-1, \\
\left(E_{k}^{h}\right)_{\alpha}^{U} & =\sum_{r=1}^{s} u_{r}^{*}\left(Y_{r k}\right)_{\alpha}^{U} / \sum_{p=1}^{q} L_{p k}^{(h-1)} .
\end{aligned}
$$

It is obvious from Model (11) that the system efficiency is obtained by multiplying all process efficiencies by each other:

$$
\begin{aligned}
& \left(E_{k}\right)_{\alpha}^{U}=\left(E_{k}^{1}\right)_{\alpha}^{U} \times\left(E_{k}^{2}\right)_{\alpha}^{U} \times \cdots \times\left(E_{k}^{t}\right)_{\alpha}^{U} \\
& t=1, \cdots, h .
\end{aligned}
$$

The relationship in Eq. (12) shows that a DMU is efficient when all the processes are efficient.

\subsubsection{Lower bound}

For finding the lower bound of general system, the procedure introduced in Subsection 5.2 is used as follows:

- Step 1: The dual of Model (7) is:

$$
\begin{aligned}
& \min \theta-\varepsilon\left(\sum_{i=1}^{m} s_{i}^{x}+\sum_{r=1}^{s} s_{r}^{y}+\sum_{t=1}^{h-1} \sum_{p=1}^{q} s_{p}^{z^{(t)}}\right), \\
& \text { s.t. } \\
& \theta X_{i k}-\sum_{j=1}^{n} \lambda_{j} X_{i j}-\sum_{j=1}^{n} \lambda_{j}^{(1)} X_{i j}-s_{i}^{x}=0, \\
& \quad i=1, \cdots, m
\end{aligned}
$$




$$
\begin{aligned}
& \sum_{j=1}^{n} \lambda_{j} Y_{r j}+\sum_{j=1}^{n} \lambda_{j}^{(h)} Y_{r j}-Y_{r k}-s_{r}^{y}=0, \\
& r=1 \cdots, s, \\
& \sum_{j=1}^{n} \lambda_{j}^{(t)} z_{p j}^{(t)}-\sum_{j=1}^{n} \lambda_{j}^{(t+1)} z_{p j}^{(t)}-s_{p}^{z^{(t)}}=0, \\
& p=1, \cdots, q, \quad t=1, \cdots, h-1, \\
& \lambda_{j}, \lambda_{j}^{(t)} \geq 0, \quad j=1, \cdots, n \quad t=1, \cdots, h, \\
& s_{i}^{x}, s_{r}^{y}, s_{p}^{z^{(t)}} \geq 0, \quad i=1, \cdots, m, \\
& r=1 \cdots, s, \quad p=1 \cdots q, \quad t=1, \cdots, h-1 .
\end{aligned}
$$

- Step 2: Using the $\alpha$-cuts introduced in Step 2 of upper bound, express the lower bound as:

$$
\begin{aligned}
\left(E_{k}\right)_{\alpha}^{L}= & \min \left(X_{i j}^{t}\right)_{\alpha}^{L} \leq x_{i j}^{t} \leq\left(X_{i j}^{t}\right)_{\alpha}^{U} E_{k}(x, z, y) \\
& \left(Z_{h j}^{t}\right)_{\alpha}^{L} \leq z_{h j}^{t} \leq\left(Z_{h j}^{t}\right)_{\alpha}^{U} \\
& \left(Y_{r j}^{t}\right)_{\alpha}^{L} \leq y_{r j}^{t} \leq\left(Y_{r j}^{t}\right)_{\alpha}^{U} \\
& \forall i, h, j, t, r
\end{aligned}
$$

where $E_{k}(x, y, z)$ is defined in Model (13).

- Step 3: By substituting the lower or upper bounds of variables introduced in the procedure of Subsection 5.2, change Model (14) to:

$$
\min \theta-\varepsilon\left(\sum_{i=1}^{m} s_{i}^{x}+\sum_{r=1}^{s} s_{r}^{y}+\sum_{t=1}^{h-1} \sum_{p=1}^{q} s_{p}^{z^{(t)}}\right)
$$

s.t.

$$
\begin{gathered}
\theta\left(X_{i k}\right)_{\alpha}^{U}-\left[\lambda_{k}\left(X_{i k}\right)_{\alpha}^{U}+\sum_{\substack{j=1 \\
j \neq k}}^{n} \lambda_{j}\left(X_{i j}\right)_{\alpha}^{L}\right] \\
-\left[\lambda_{k}^{(1)}\left(X_{i k}\right)_{\alpha}^{U}+\sum_{\substack{j=1 \\
j \neq k}}^{n} \lambda_{j}^{(1)}\left(X_{i j}\right)_{\alpha}^{L}\right]-s_{i}^{x}=0,
\end{gathered}
$$$$
i=1, \cdots, m \text {, }
$$

$$
\begin{aligned}
& {\left[\lambda_{k}\left(Y_{r k}\right)_{\alpha}^{L}+\sum_{\substack{j=1 \\
j \neq k}}^{n} \lambda_{j}\left(Y_{r j}\right)_{\alpha}^{U}\right]} \\
& +\left[\lambda_{k}^{(h)}\left(Y_{r k}\right)_{\alpha}^{L}+\sum_{\substack{j=1 \\
j \neq k}}^{n} \lambda_{j}^{(h)}\left(Y_{r j}\right)_{\alpha}^{U}\right] \\
& -\left(Y_{r k}\right)_{\alpha}^{L}-s_{r}^{y}=0, \quad r=1 \cdots, s, \\
& \sum_{j=1}^{n} \lambda_{j}^{(t)} z_{p j}^{(t)}-\sum_{j=1}^{n} \lambda_{j}^{(t+1)} z_{p j}^{(t)}-s_{p}^{z^{(t)}}=0 \\
& p=1, \cdots, q, \quad t=1, \cdots, h-1, \\
& \left(Z_{p j}^{(t)}\right)_{\alpha}^{L} \leq z_{p j}^{(t)} \leq\left(Z_{p j}^{(t)}\right)_{\alpha}^{U} \\
& p=1, \cdots, q, \quad t=1, \cdots, h-1, \\
& \lambda_{j}, \lambda_{j}^{(t)} \geq 0, \quad j=1, \cdots, n, \quad t=1, \cdots, h, \\
& s_{i}^{x}, s_{r}^{y}, s_{p}^{z^{(t)}} \geq 0, \quad i=1, \cdots, m, \\
& r=1 \cdots, s, \quad p=1, \cdots, q, \\
& t=1, \cdots, h-1
\end{aligned}
$$

- Step 4: Model (15) is nonlinear model terms of $\lambda_{j}^{(t)} z_{p j}^{(t)}$. Therefore, in order to transform it into linear programming, assume:

$$
\begin{array}{cl}
M_{p j}^{(t)}=\lambda_{j}^{(t)} z_{p j}^{(t)}, & t=1, \cdots, h-1 ; \\
p=1, \cdots, q ; & j=1, \cdots, n, \\
\hat{M}_{p j}^{(t)}=\lambda_{j}^{(t+1)} z_{p j}^{(t)}, & t=1, \cdots, h-1 ;
\end{array}
$$$$
p=1, \cdots, q ; \quad j=1, \cdots, n .
$$

Multiply each term in constraints $\left(Z_{p j}^{(t)}\right)_{\alpha}^{L} \leq z_{p j}^{(t)} \leq$ $\left(Z_{p j}^{(t)}\right)_{\alpha}^{U}$ one time by $\lambda_{j}^{(t)}$ and another time by $\lambda_{j}^{(t+1)}$; then, add two new constraints to the model. By substituting Model (16) into Model (15), Model (15) changes to a linear programming as follows:

$$
\min \theta-\varepsilon\left(\sum_{i=1}^{m} s_{i}^{x}+\sum_{r=1}^{s} s_{r}^{y}+\sum_{t=1}^{h-1} \sum_{p=1}^{q} s_{p}^{z^{(t)}}\right)
$$

s.t. 


$$
\begin{aligned}
& \theta\left(X_{i k}\right)_{\alpha}^{U}-\left[\lambda_{k}\left(X_{i k}\right)_{\alpha}^{U}+\sum_{\substack{j=1 \\
j \neq k}}^{n} \lambda_{j}\left(X_{i j}\right)_{\alpha}^{L}\right] \\
& -\left[\lambda_{k}^{(1)}\left(X_{i k}\right)_{\alpha}^{U}+\sum_{\substack{j=1 \\
j \neq k}}^{n} \lambda_{j}^{(1)}\left(X_{i j}\right)_{\alpha}^{L}\right]-s_{i}^{x}=0, \\
& i=1, \cdots, m, \\
& {\left[\lambda_{k}\left(Y_{r k}\right)_{\alpha}^{L}+\sum_{\substack{j=1 \\
j \neq k}}^{n} \lambda_{j}\left(Y_{r j}\right)_{\alpha}^{U}\right]} \\
& +\left[\lambda_{k}^{(h)}\left(Y_{r k}\right)_{\alpha}^{L}+\sum_{\substack{j=1 \\
j \neq k}}^{n} \lambda_{j}^{(h)}\left(Y_{r j}\right)_{\alpha}^{U}\right] \\
& -\left(Y_{r k}\right)_{\alpha}^{L}-s_{r}^{y}=0, \quad r=1 \cdots, s, \\
& \sum_{j=1}^{n} M_{p j}^{(t)}-\sum_{j=1}^{n} \hat{M}_{p j}^{(t)}-s_{p}^{z^{(t)}}=0 \\
& p=1, \cdots, q, \quad t=1, \cdots, h-1, \\
& \lambda_{j}^{(t)}\left(Z_{p j}^{(t)}\right)_{\alpha}^{L} \leq M_{p j}^{(t)} \leq \lambda_{j}^{(t)}\left(Z_{p j}^{(t)}\right)_{\alpha}^{U}, \\
& p=1, \cdots, q, \quad t=1, \cdots, h-1, \\
& \lambda_{j}^{(t+1)}\left(Z_{p j}^{(t)}\right)_{\alpha}^{L} \leq \hat{M}_{p j}^{(t)} \leq \lambda_{j}^{(t+1)}\left(Z_{p j}^{(t)}\right)_{\alpha}^{U}, \\
& p=1, \cdots, q, \quad t=1, \cdots, h-1, \\
& \lambda_{j}, \lambda_{j}^{(t)} \geq 0, \quad j=1, \cdots, n \quad t=1, \cdots, h, \\
& s_{i}^{x}, s_{r}^{y}, s_{p}^{z^{(t)}} \geq 0, \quad i=1, \cdots, m ; \\
& r=1 \cdots, s ; \quad p=1, \cdots, q ; \\
& t=1, \cdots, h-1 .
\end{aligned}
$$

The optimal values of $M_{p j}^{(t)}, \lambda_{j}^{(t)}, \lambda_{j}^{(t+1)}$, and $\hat{M}_{p j}^{(t)}$ are obtained from Model (17). The optimal value of $Z_{p j}^{(t)}$ is achieved by substituting these parameters into Model (16). The reduced costs of optimum values of $s_{i}^{x}, s_{p}^{z^{(t)}}$, and $s_{r}^{y}$, achieved from Model (17), are the values of multipliers $v_{i}, w_{p}^{(t)}$, and $u_{r}$, respectively, of the primal model. Therefore, the efficiency of subprocesses is calculated as follows:

$$
\begin{aligned}
&\left(E_{k}\right)_{\alpha}^{L}=\sum_{r=1}^{s} u_{r}^{*}\left(Y_{r k}\right)_{\alpha}^{L} / \sum_{i=1}^{m} v_{i}^{*}\left(X_{i k}\right)_{\alpha}^{U} \\
&\left(E_{k}^{1}\right)_{\alpha}^{L}=\sum_{p=1}^{q} w_{p}^{*(1)} z_{p k}^{*(1)} / \sum_{i=1}^{m} v_{i}^{*}\left(X_{i k}\right)_{\alpha}^{U}, \\
&\left(E_{k}^{t}\right)_{\alpha}^{L}=\sum_{p=1}^{q} w_{p}^{*(t)} z_{p k}^{*(t)} / \sum_{p=1}^{q} w_{p}^{*(t-1)} z_{p k}^{*(t-1)} \\
& t=2, \cdots, h-1, \\
&\left(E_{k}^{h}\right)_{\alpha}^{L}=\sum_{r=1}^{s} u_{r}^{*}\left(Y_{r k}\right)_{\alpha}^{L} / \sum_{p=1}^{q} w_{p}^{*(h-1)} z_{p k}^{*(h-1)} .
\end{aligned}
$$

It is obvious from Model (18) that system efficiency is achieved by multiplying all process efficiencies by each other:

$$
\begin{aligned}
& \left(E_{k}\right)_{\alpha}^{L}=\left(E_{k}^{1}\right)_{\alpha}^{L} \times\left(E_{k}^{2}\right)_{\alpha}^{L} \times \cdots \times\left(E_{k}^{t}\right)_{\alpha}^{L}, \\
& t=1, \cdots, h .
\end{aligned}
$$

The relationship in Eq. (19) shows that the system is efficient when all the processes are efficient.

\section{Fuzzy relational network DEA}

This section presents the relational network DEA with fuzzy data. Since the structure of any network system is different, this paper uses the network of a shipping firm in Iran (case study of this paper), which is shown in Figure 2, to introduce fuzzy relational network DEA model. This system has 8 processes linked by intermediate products. Processes 1 to 4 use inputs $X_{1}, X_{2}, X_{3}$, and $X_{4}$ to produce intermediate products $Z_{1}, Z_{2}, Z_{3}$, and $Z_{4}$, respectively; Process 5 uses intermediate products $Z_{1}, Z_{2}, Z_{3}$, and $Z_{4}$, produced by processes 1 to 4 , respectively, to produce intermediate products $Z_{51}$ and $Z_{52}$; Process 6 uses intermediate product $Z_{51}$ and input $X_{5}$ to produce intermediate product $Z_{6}$; process 7 uses intermediate product $Z_{52}$ and input $X_{6}$ to produce intermediate product $Z_{7}$; and, finally, process 8 uses intermediate products $Z_{6}$ and $Z_{7}$ to produce final output $Y$.

The relational network DEA model for calculating efficiency of the system given in Figure 2 is as follows:

$$
\begin{aligned}
& E_{k}=\max u Y_{k}, \\
& \text { s.t. } \\
& \begin{aligned}
v_{1} X_{1 k} & +v_{2} X_{2 k}+v_{3} X_{3 k}+v_{4} X_{4 k}+v_{5} X_{5 k} \\
& +v_{6} X_{6 k}=1
\end{aligned}
\end{aligned}
$$




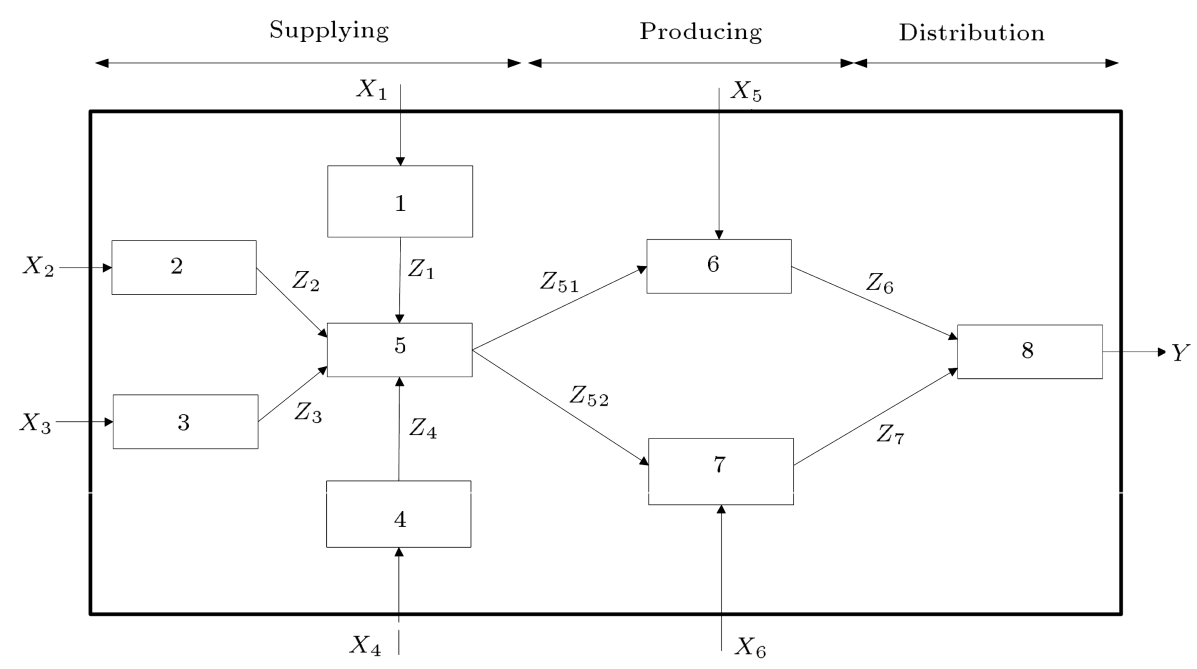

Figure 2. Network system of the shipping line.

$$
\begin{array}{cc}
\begin{array}{c}
u Y_{j}-\left(v_{1} X_{1 j}+v_{2} X_{2 j}+v_{3} X_{3 j}+v_{4} X_{4 j}\right. \\
\left.+v_{5} X_{5 j}+v_{6} X_{6 j}\right) \leq 0,
\end{array} \quad j=1, \cdots, n, & j=1, \cdots, n, \\
w_{1} Z_{1 j}-v_{1} X_{1 j} \leq 0, & j=1, \cdots, n, \\
w_{2} Z_{2 j}-v_{2} X_{2 j} \leq 0, & j=1, \cdots, n, \\
w_{3} Z_{3 j}-v_{3} X_{3 j} \leq 0, & j=1, \cdots, n, \\
w_{4} Z_{4 j}-v_{4} X_{4 j} \leq 0, & \\
w_{51} Z_{51 j}+w_{52} Z_{52 j}-\left(w_{1} Z_{1 j}\right. & +w_{2} Z_{2 j} \\
\left.+w_{3} Z_{3 j}+w_{4} Z_{4 j}\right) \leq 0, & j=1, \cdots, n, \\
w_{6} Z_{6 j}-\left(w_{51} Z_{51 j}+v_{5} X_{5 j}\right) \leq 0, & j=1, \cdots, n, \\
w_{7} Z_{7 j}-\left(w_{52} Z_{52 j}+v_{6} X_{6 j}\right) \leq 0, & j=1, \cdots, n, \\
u Y_{j}-\left(w_{6} Z_{6 j}+w_{7} Z_{7 j}\right) \leq 0, & j=1, \cdots, n,
\end{array}
$$

$$
u, v_{i}, w_{h} \geq \varepsilon, \quad i=1, \cdots 6, \quad h=1,2,3,4,51,52,6,7,
$$

where $v_{i}$ is the multiplier associated with the input $i$, $i=1, \cdots, 6 ; u$ is the multiplier associated with output; and $w_{h}, h=1,2,3,4,51,52,6,7$, is the multiplier associated with the intermediate product.

In this model, the constraint set in Eq. (20.2) corresponds to the system and states that the system output must essentially be less than or equal to system inputs for all DMUs. Constraint sets in Eqs. (20.3) to $(20.10)$ correspond to processes 1 to 8 , respectively, and state that the outputs of each process must essentially be less than or equal to the inputs of that process for all DMUs. A characteristic of Model (20) is that every intermediate product has the same multiplier, regardless of whether it is treated as the output or the input of the process. For example, intermediate product, $Z_{6}$, always has the multiplier, $w_{6}$, no matter whether it performs as the input of process 8 or the output of process 6 . Denote $u^{*}, v_{i}^{*}$, and $w_{h}^{*}$ as the optimal solution to DMU $k$. The efficiency of the process is defined as the proportion of weighted sum of outputs to weighted sum of inputs for any process. Therefore, the efficiencies of processes are as follows:

$$
\begin{aligned}
E_{k}^{1}= & w_{1}^{*} Z_{1 k} / v_{1}^{*} X_{1 k}, \quad E_{k}^{2}=w_{2}^{*} Z_{2 k} / v_{2}^{*} X_{2 k}, \\
E_{k}^{3}= & w_{3}^{*} Z_{3 k} / v_{3}^{*} X_{3 k}, \quad E_{k}^{4}=w_{4}^{*} Z_{4 k} / v_{4}^{*} X_{4 k}, \\
E_{k}^{5}= & \left(w_{51}^{*} Z_{51 k}+w_{52}^{*} Z_{52 k}\right) /\left(w_{1}^{*} Z_{1 k}+w_{2}^{*} Z_{2 k}\right. \\
& \left.\quad+w_{3}^{*} Z_{3 k}+w_{4}^{*} Z_{4 k}\right) \\
E_{k}^{6}= & w_{6}^{*} Z_{6 k} /\left(w_{51}^{*} Z_{51 k}+v_{5}^{*} X_{5 k}\right) \\
E_{k}^{7}= & w_{7}^{*} Z_{7 k} /\left(w_{52}^{*} Z_{52 k}+v_{6}^{*} X_{6 k}\right), \\
E_{k}^{8}= & u^{*} Y_{k} /\left(w_{6}^{*} Z_{6 k}+w_{7}^{*} Z_{7 k}\right) .
\end{aligned}
$$

The dual (envelopment) form of Model (20) is as follows:

$$
\begin{aligned}
E_{k}=\min \theta-\varepsilon & \left(\sum_{i=1}^{6} s_{i}^{x}+\sum_{i=1}^{4} s_{i}^{z}+s_{51}^{z}+s_{52}^{z}\right. \\
& \left.+s_{6}^{z}+s_{7}^{z}+s^{y}\right)
\end{aligned}
$$

s.t.

$$
\theta X_{i k}-\sum_{j=1}^{n} \alpha_{j} X_{i j}-\sum_{j=1}^{n} \lambda_{j}^{(i)} X_{i j}-s_{i}^{x}=0
$$


$i=1,2,3,4$,

$\theta X_{5 k}-\sum_{j=1}^{n} \alpha_{j} X_{5 j}-\sum_{j=1}^{n} \lambda_{j}^{(6)} X_{5 j}-s_{5}^{x}=0$

$\theta X_{6 k}-\sum_{j=1}^{n} \alpha_{j} X_{6 j}-\sum_{j=1}^{n} \lambda_{j}^{(7)} X_{6 j}-s_{6}^{x}=0$

$\sum_{j=1}^{n} \alpha_{j} Y_{j}+\sum_{j=1}^{n} \lambda_{j}^{(8)} Y_{j}-s^{y}=Y_{k}$

$\sum_{j=1}^{n} \lambda_{j}^{(q)} Z_{q j}-\sum_{j=1}^{n} \lambda_{j}^{(5)} Z_{q j}-s_{q}^{z}=0$

$$
q=1, \cdots, 4
$$

$\sum_{j=1}^{n} \lambda_{j}^{(5)} Z_{51 j}-\sum_{j=1}^{n} \lambda_{j}^{(6)} Z_{51 j}-s_{51}^{z}=0$

$$
\sum_{j=1}^{n} \lambda_{j}^{(5)} Z_{52 j}-\sum_{j=1}^{n} \lambda_{j}^{(7)} Z_{52 j}-s_{52}^{z}=0
$$

$$
\sum_{j=1}^{n} \lambda_{j}^{(6)} Z_{6 j}-\sum_{j=1}^{n} \lambda_{j}^{(8)} Z_{6 j}-s_{6}^{z}=0
$$

$$
\sum_{j=1}^{n} \lambda_{j}^{(7)} Z_{7 j}-\sum_{j=1}^{n} \lambda_{j}^{(8)} Z_{7 j}-s_{7}^{z}=0
$$$$
\alpha_{j}, \lambda_{j}^{(t)}, s_{i}^{x}, s_{h}^{z}, s^{y} \geq 0, \quad i=1, \cdots, 6,
$$$$
t=1, \cdots, 8, \quad h=1,2,3,4,51,52,6,7,
$$

$$
j=1, \cdots, n,
$$

where $\theta, \alpha$, and $\lambda^{(1)}$ to $\lambda^{(8)}$ are related to dual variables of Eqs. (20.1) to (20.10), respectively. The set of Eqs. (22.1) to (22.4) corresponds to the inputs and final output of the system, respectively. $\sum_{j=1}^{n} \lambda_{j}^{*(t)} Z_{h j}$ stands for the target value of intermediate product $Z_{h j}$ on optimality. Eqs. (22.5) to (22.9) correspond to intermediate products, one for each of them, and state that the target value of an intermediate product, when acting as the output of the process that produces it, must essentially be greater than or equal to when it acts as the input of the process that consumes it.

As the network structure under study does not conform to the fuzzy relational DEA presented for general structure, a new model has been developed for this network structure.

By considering a part or all of the inputs and outputs as imprecise data, the fuzzy concepts are used to describe them. Assume that the inputs $\tilde{X}_{i j}$, intermediates $\tilde{Z}_{h j}$, and outputs $\tilde{Y}_{j}$ are approximately known and can be shown by fuzzy sets with membership functions $\mu_{\tilde{X}_{i j}}, \mu_{\tilde{Z}_{h j}}$, and $\mu_{\tilde{Y}_{j}}$, respectively. Based on Zadeh's extension principle [47], the membership function is described as follows:

$$
\begin{aligned}
& \mu_{\tilde{E}_{k}}(g)=\sup \min \left\{\mu_{\tilde{X}_{i j}}\left(x_{i j}\right), \mu_{\tilde{Z}_{h j}}\left(z_{h j}\right), \mu_{\tilde{Y}_{j}}\left(y_{j}\right),\right. \\
& \left.\quad \forall i, j, h \mid g=E_{k}(x, z, y)\right\},
\end{aligned}
$$

where $E_{k}(x, z, y)$ is defined in Model (20); in this case, $x_{i j}, z_{h j}$, and $y_{j}$ (symbolized by lower case letters) are variables to be determined, rather than given constants, which are represented by upper case letters.

For $\alpha$-cuts of $\tilde{X}_{i j}, \tilde{Z}_{h j}$, and $\tilde{Y}_{j}$, let $\left(X_{i j}\right)_{\alpha}=$ $\left[\left(X_{i j}\right)_{\alpha}^{L},\left(X_{i j}\right)_{\alpha}^{U}\right], \quad\left(Z_{h j}\right)_{\alpha}=\left[\left(Z_{h j}\right)_{\alpha}^{L},\left(Z_{h j}\right)_{\alpha}^{U}\right]$, and $\left(Y_{j}\right)_{\alpha}=\left[\left(Y_{j}\right)_{\alpha}^{L},\left(Y_{j}\right)_{\alpha}^{U}\right]$, respectively. To find the membership function $\mu_{\tilde{E}_{k}}(g)$, it suffices to find the upper and lower bounds of the $\alpha$-cut off $\tilde{E}_{k}$, which, based on Eq. (6), can be solved by:

$$
\begin{aligned}
\left(E_{k}\right)_{\alpha}^{U}= & \max \left(X_{i j}\right)_{\alpha}^{L} \leq x_{i j} \leq\left(X_{i j}\right)_{\alpha}^{U} E_{k}(x, z, y), \\
& \left(Z_{h j}\right)_{\alpha}^{L} \leq z_{h j} \leq\left(Z_{h j}\right)_{\alpha}^{U} \\
& \left(Y_{j}\right)_{\alpha}^{L} \leq y_{j} \leq\left(Y_{j}\right)_{\alpha}^{U} \\
& \forall i, h, j, \\
\left(E_{k}\right)_{\alpha}^{L}= & \left.\quad \min { } E_{i j}\right)_{\alpha}^{L} \leq x_{i j} \leq\left(X_{i j}\right)_{\alpha}^{U} E_{k}(x, z, y) . \\
& \left(Z_{h j}\right)_{\alpha}^{L} \leq z_{h j} \leq\left(Z_{h j}\right)_{\alpha}^{U} \\
& \left(Y_{j}\right)_{\alpha}^{L} \leq y_{j} \leq\left(Y_{j}\right)_{\alpha}^{U} \\
& \forall i, h, j .
\end{aligned}
$$

Models (24) and (25) are two-level mathematical programming only used for modeling. Therefore, for solving two-level mathematical programming, it must be transformed into one-level programming. In this kind of problem, first, the values of $x_{i j}, z_{h j}$, and $y_{j}$ must be found, which help to find the upper and lower efficiencies. Then, the inner program should be solved. For this purpose, in the next section, upper and lower bounds of the model will be found.

\subsection{Upper bound}

The procedure that leads to finding the values of $x_{i j}$, $z_{h j}$, and $y_{j}$ for maximizing the efficiency of DMU $k$ and converting the two-level mathematical programing of upper bound into one-level programing is represented as follows:

1. Substituting the largest value of all outputs and smallest value of all inputs for DMU $\mathrm{k}$ in the Model (24);

2. Substituting the smallest value of all outputs and largest value of all inputs for other DMU in the Model (24). 


$$
\begin{aligned}
& \begin{aligned}
\left(E_{k}\right)_{\alpha}^{U}= & \max \left(Z_{h j}\right)_{\alpha}^{L} \leq z_{h j} \leq\left(Z_{h j}\right)_{\alpha}^{U} \\
& \forall h, j
\end{aligned}
\end{aligned}
$$

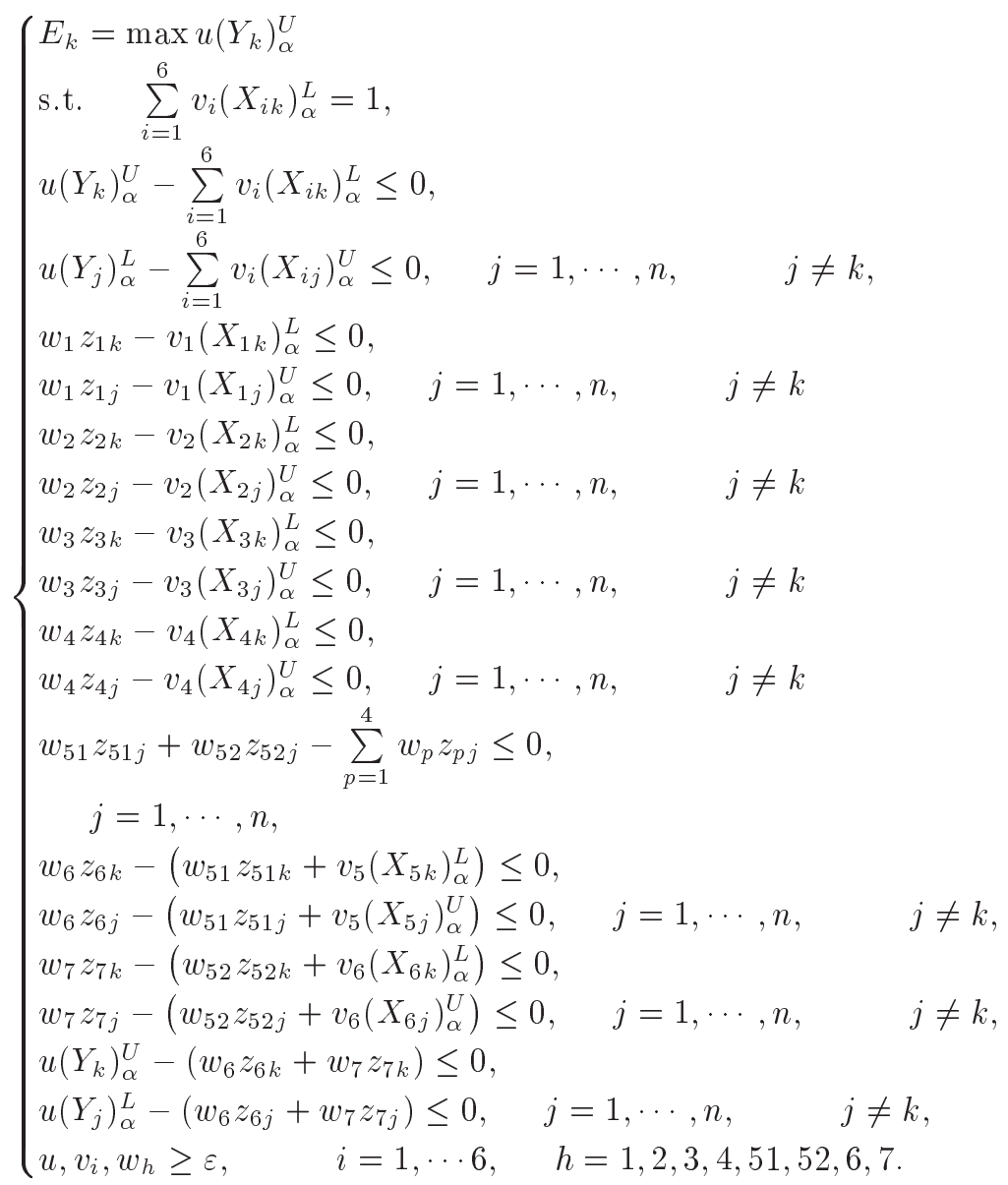

Box I

After substitutions according to the above description, Model (24), in full form, it changes as shown in Box I.

Model (26) is still two-level programming and the value of $z_{h j}$ must be determined to convert it into onelevel programing. Since both inner programing and outer programing have the same direction, they can be easily reduced to a one-level optimization problem by substituting the constraints of the outer program into the model of inner program as follows:

$\left(E_{k}\right)_{\alpha}^{U}=\max u\left(Y_{k}\right)_{\alpha}^{U}$

s.t.

$\sum_{i=1}^{6} v_{i}\left(X_{i k}\right)_{\alpha}^{L}=1$

$$
u\left(Y_{k}\right)_{\alpha}^{U}-\sum_{i=1}^{6} v_{i}\left(X_{i k}\right)_{\alpha}^{L} \leq 0
$$$$
u\left(Y_{j}\right)_{\alpha}^{L}-\sum_{i=1}^{6} v_{i}\left(X_{i j}\right)_{\alpha}^{U} \leq 0,
$$$$
j=1, \cdots, n, \quad j \neq k,
$$

$w_{1} z_{1 k}-v_{1}\left(X_{1 k}\right)_{\alpha}^{L} \leq 0$

$w_{1} z_{1 j}-v_{1}\left(X_{1 j}\right)_{\alpha}^{U} \leq 0 q q u a d j=1, \cdots, n, \quad j \neq k$,

$w_{2} z_{2 k}-v_{2}\left(X_{2 k}\right)_{\alpha}^{L} \leq 0$ 


$$
\begin{aligned}
& w_{2} z_{2 j}-v_{2}\left(X_{2 j}\right)_{\alpha}^{U} \leq 0, \quad j=1, \cdots, n, \quad j \neq k, \\
& w_{3} z_{3 k}-v_{3}\left(X_{3 k}\right)_{\alpha}^{L} \leq 0, \\
& w_{3} z_{3 j}-v_{3}\left(X_{3 j}\right)_{\alpha}^{U} \leq 0, \quad j=1, \cdots, n, \quad j \neq k, \\
& w_{4} z_{4 k}-v_{4}\left(X_{4 k}\right)_{\alpha}^{L} \leq 0, \\
& w_{4} z_{4 j}-v_{4}\left(X_{4 j}\right)_{\alpha}^{U} \leq 0, \quad j=1, \cdots, n, \quad j \neq k, \\
& w_{51} z_{51 j}+w_{52} z_{52 j}-\sum_{p=1}^{4} w_{p} z_{p j} \leq 0, \\
& j=1, \cdots, n, \quad j \neq, \quad j \neq k, \\
& w_{6} z_{6 k}-\left(w_{51} z_{51 k}+v_{5}\left(X_{5 k}\right)_{\alpha}^{L}\right) \leq 0, \\
& w_{6} z_{6 j}-\left(w_{51} z_{51 j}+v_{5}\left(X_{5 j}\right)_{\alpha}^{U}\right) \leq 0, \\
& j=1, \cdots, n, \quad j \neq k, \\
& w_{7} z_{7 k}-\left(w_{52} z_{52 k}+v_{6}\left(X_{6 k}\right)_{\alpha}^{L}\right) \leq 0, \\
& w_{7} z_{7 j}-\left(w_{52} z_{52 j}+v_{6}\left(X_{6 j}\right)_{\alpha}^{U}\right) \leq 0, \\
& j=1, \cdots, n, \\
& j \neq k, u\left(Y_{k}\right)_{\alpha}^{U}-\left(w_{6} z_{6 k}+w_{7} z_{7 k}\right) \leq 0, \\
& \quad j=1, \cdots, n, \quad j\left(Y_{j}\right)_{\alpha}^{L}-\left(w_{6} z_{6 j}+w_{7} z_{7 j}\right) \leq 0, \\
& \left(Z_{h j}\right)_{\alpha}^{L} \leq z_{h j} \leq\left(Z_{h j}\right)_{\alpha}^{U}, \quad j=1, \cdots, n, \\
& h=1,2,3,4,51,52,6,7, \\
& j=0,
\end{aligned}
$$$$
u, v_{i}, w_{h} \geq \varepsilon, \quad i=1, \cdots, 6,
$$$$
h=1,2,3,4,51,52,6,7 .
$$

Model (27) is nonlinear due to the nonlinear terms $w_{h} z_{h j}$; therefore, to transform it into linear programming, assume:

$$
L_{h j}=w_{h} z_{h j}, \quad h=1,2,3,4,51,52,6,7 .
$$

By substituting Model (28) into Model (27), the model changes to a linear one as follows:

$$
\left(E_{k}\right)_{\alpha}^{U}=\max u\left(Y_{k}\right)_{\alpha}^{U},
$$

s.t. $\sum_{i=1}^{6} v_{i}\left(X_{i k}\right)_{\alpha}^{L}=1$

$u\left(Y_{k}\right)_{\alpha}^{U}-\sum_{i=1}^{6} v_{i}\left(X_{i k}\right)_{\alpha}^{L} \leq 0$,

$u\left(Y_{j}\right)_{\alpha}^{L}-\sum_{i=1}^{6} v_{i}\left(X_{i j}\right)_{\alpha}^{U} \leq 0$,

$j=1, \cdots, n, \quad j \neq k$,

$L_{1 k}-v_{1}\left(X_{1 k}\right)_{\alpha}^{L} \leq 0$,

$L_{1 j}-v_{1}\left(X_{1 j}\right)_{\alpha}^{U} \leq 0, \quad j=1, \cdots, n, \quad j \neq k$,

$L_{2 k}-v_{2}\left(X_{2 k}\right)_{\alpha}^{L} \leq 0$,

$L_{2 j}-v_{2}\left(X_{2 j}\right)_{\alpha}^{U} \leq 0, \quad j=1, \cdots, n, \quad j \neq k$,

$L_{3 k}-v_{3}\left(X_{3 k}\right)_{\alpha}^{L} \leq 0$,

$L_{3 j}-v_{3}\left(X_{3 j}\right)_{\alpha}^{U} \leq 0, \quad j=1, \cdots, n, \quad j \neq k$,

$L_{4 k}-v_{4}\left(X_{4 k}\right)_{\alpha}^{L} \leq 0$,

$L_{4 j}-v_{4}\left(X_{4 j}\right)_{\alpha}^{U} \leq 0, \quad j=1, \cdots, n, \quad j \neq k$,

$L_{51 j}+L_{52 j}-\sum_{p=1}^{4} L_{p j} \leq 0, \quad j=1, \cdots, n$,

$L_{6 k}-\left(L_{51 k}+v_{5}\left(X_{5 k}\right)_{\alpha}^{L}\right) \leq 0$,

$L_{6 j}-\left(L_{51 j}+v_{5}\left(X_{5 j}\right)_{\alpha}^{U}\right) \leq 0, \quad j=1, \cdots, n, \quad j \neq k$,

$L_{7 k}-\left(L_{52 k}+v_{6}\left(X_{6 k}\right)_{\alpha}^{L}\right) \leq 0$,

$L_{7 j}-\left(L_{52 j}+v_{6}\left(X_{6 j}\right)_{\alpha}^{U}\right) \leq 0$,

$j=1, \cdots, n, \quad j \neq k$

$u\left(Y_{k}\right)_{\alpha}^{U}-\left(L_{6 k}+L_{7 k}\right) \leq 0$,

$u\left(Y_{j}\right)_{\alpha}^{L}-\left(L_{6 j}+L_{7 j}\right) \leq 0$,

$$
j=1, \cdots, n, \quad j \neq k,
$$

$w_{h}\left(Z_{h j}\right)_{\alpha}^{L} \leq L_{h j} \leq w_{h}\left(Z_{h j}\right)_{\alpha}^{U}$,

$j=1, \cdots, n, \quad h=1,2,3,4,51,52,6,7$,

$u, v_{i}, w_{h} \geq \varepsilon, \quad i=1, \cdots, 6, \quad h=1,2,3,4,51,52,6,7$.

$u^{*}, v_{i}^{*}, w_{h}^{*}$, and $L_{h j}^{*}$ are the optimal solution to DMU $k$. 
The efficiency of the process is defined as the proportion of weighted sum of outputs to the weighted sum of inputs for any process. Therefore, the efficiencies of processes are as follows:

$$
\begin{aligned}
& \left(E_{k}^{1}\right)_{\alpha}^{U}=L_{1 k}^{*} / v_{1}^{*}\left(X_{1 k}\right)_{\alpha}^{L}\left(E_{k}^{2}\right)_{\alpha}^{U}=L_{2 k}^{*} / v_{2}^{*}\left(X_{2 k}\right)_{\alpha}^{L}, \\
& \left(E_{k}^{3}\right)_{\alpha}^{U}=L_{3 k}^{*} / v_{3}^{*}\left(X_{3 k}\right)_{\alpha}^{L}\left(E_{k}^{4}\right)_{\alpha}^{U}=L_{4 k}^{*} / v_{4}^{*}\left(X_{4 k}\right)_{\alpha}^{L}, \\
& \left(E_{k}^{5}\right)_{\alpha}^{U}=\left(L_{51 k}^{*}+L_{52 k}^{*}\right) /\left(L_{1 k}^{*}+L_{2 k}^{*}+L_{3 k}^{*}+L_{4 k}^{*}\right) \\
& \left(E_{k}^{6}\right)_{\alpha}^{U}=L_{6 k}^{*} /\left(L_{51 k}^{*}+v_{5}^{*}\left(X_{5 k}\right)_{\alpha}^{L}\right) \\
& \left(E_{k}^{7}\right)_{\alpha}^{U}=L_{7 k}^{*} /\left(L_{52 k}^{*}+v_{6}^{*}\left(X_{6 k}\right)_{\alpha}^{L}\right) \\
& \left(E_{k}^{8}\right)_{\alpha}^{U}=u^{*}\left(Y_{k}\right)_{\alpha}^{U} /\left(L_{6 k}^{*}+L_{7 k}^{*}\right) .
\end{aligned}
$$

\subsection{Lower bound}

The procedure that leads to finding the values of $x_{i j}$, $z_{h j}$, and $y_{j}$ for minimizing the efficiency of DMU $k$ is represented as follows:

1. Substitute the largest value of all outputs and the smallest value of all inputs with DMU $k$ in Model (24);

2. Substitute the smallest value of all outputs and the largest value of all inputs with the other DMU in Model (24).

After substitutions according to the above descriptions for Model (24), in full form, it changes as shown in Box II. The procedure for converting the two-level programming into a one-level program in lower bound is not as much direct as the upper bound procedure because the directions of outer and inner programs are different. In the two-level programming, when the directions of outer and inner programs are different, substituting the constraint of the outer program into the inner program may increase or decrease the efficiency in comparison with its real value. Therefore, the direction of Model (31) must change. However, as the direction of the outer program cannot change, the direction of the inner program must be changed. By utilizing the duality theorem, the direction of inner program changes from maximization to minimization. Model (22) is the dual form of inner program of Model (31). Hence, the directions of both inner and outer programs change to minimization, which can be easily reduced to a single-level program. Furthermore, by substituting the most favorable bounds of $x_{i j}$ and $y_{j}$, Model (22) becomes:

$$
\begin{aligned}
\left(E_{k}\right)_{\alpha}^{L}= & \min \theta-\varepsilon\left(\sum_{i=1}^{6} s_{i}^{x}+\sum_{i=1}^{4} s_{i}^{z}\right. \\
& \left.+s_{51}^{z}+s_{52}^{z}+s_{6}^{z}+s_{7}^{z}+s^{y}\right),
\end{aligned}
$$

s.t.

$$
\begin{aligned}
& \theta\left(X_{i k}\right)_{\alpha}^{U}-\left[\alpha_{k}\left(X_{i k}\right)_{\alpha}^{U}+\sum_{j=1, j \neq k}^{n} \alpha_{j}\left(X_{i j}\right)_{\alpha}^{L}\right] \\
& -\left[\lambda_{k}^{(i)}\left(X_{i k}\right)_{\alpha}^{U}+\sum_{j=1, j \neq k}^{n} \lambda_{j}^{(i)}\left(X_{i j}\right)_{\alpha}^{L}\right] \\
& -s_{i}^{x}=0, \quad i=1,2,3,4, \\
& \theta\left(X_{5 k}\right)_{\alpha}^{U}-\left[\alpha_{k}\left(X_{5 k}\right)_{\alpha}^{U}+\sum_{j=1, j \neq k}^{n} \alpha_{j}\left(X_{5 j}\right)_{\alpha}^{L}\right] \\
& -\left[\lambda_{k}^{(6)}\left(X_{5 k}\right)_{\alpha}^{U}+\sum_{j=1, j \neq k}^{n} \lambda_{j}^{(6)}\left(X_{5 j}\right)_{\alpha}^{L}\right] \\
& -s_{5}^{x}=0, \\
& \theta\left(X_{6 k}\right)_{\alpha}^{U}-\left[\alpha_{k}\left(X_{6 k}\right)_{\alpha}^{U}+\sum_{j=1, j \neq k}^{n} \alpha_{j}\left(X_{6 j}\right)_{\alpha}^{L}\right] \\
& -\left[\lambda_{k}^{(7)}\left(X_{6 k}\right)_{\alpha}^{U}+\sum_{j=1, j \neq k}^{n} \lambda_{j}^{(7)}\left(X_{6 j}\right)_{\alpha}^{L}\right] \\
& -s_{6}^{x}=0,
\end{aligned}
$$$$
\begin{gathered}
{\left[\alpha_{k}\left(Y_{k}\right)_{\alpha}^{L}+\sum_{j=1, j \neq k}^{n} \alpha_{j}\left(Y_{j}\right)_{\alpha}^{U}\right]} \\
+\left[\lambda_{k}^{(8)}\left(Y_{k}\right)_{\alpha}^{L}+\sum_{j=1, j \neq k}^{n} \lambda_{j}^{(8)}\left(Y_{j}\right)_{\alpha}^{U}\right]-s^{y}=\left(Y_{k}\right)_{\alpha}^{L},
\end{gathered}
$$$$
\sum_{j=1}^{n} \lambda_{j}^{(q)} z_{q j}-\sum_{j=1}^{n} \lambda_{j}^{(5)} z_{q j}-s_{q}^{z}=0, \quad q=1, \cdots, 4,
$$$$
\sum_{j=1}^{n} \lambda_{j}^{(5)} z_{51 j}-\sum_{j=1}^{n} \lambda_{j}^{(6)} z_{51 j}-s_{51}^{z}=0
$$$$
\sum_{j=1}^{n} \lambda_{j}^{(5)} z_{52 j}-\sum_{j=1}^{n} \lambda_{j}^{(7)} z_{52 j}-s_{52}^{z}=0
$$$$
\sum_{j=1}^{n} \lambda_{j}^{(6)} z_{6 j}-\sum_{j=1}^{n} \lambda_{j}^{(8)} z_{6 j}-s_{6}^{z}=0
$$$$
\sum_{j=1}^{n} \lambda_{j}^{(7)} z_{7 j}-\sum_{j=1}^{n} \lambda_{j}^{(8)} z_{7 j}-s_{7}^{z}=0
$$ 


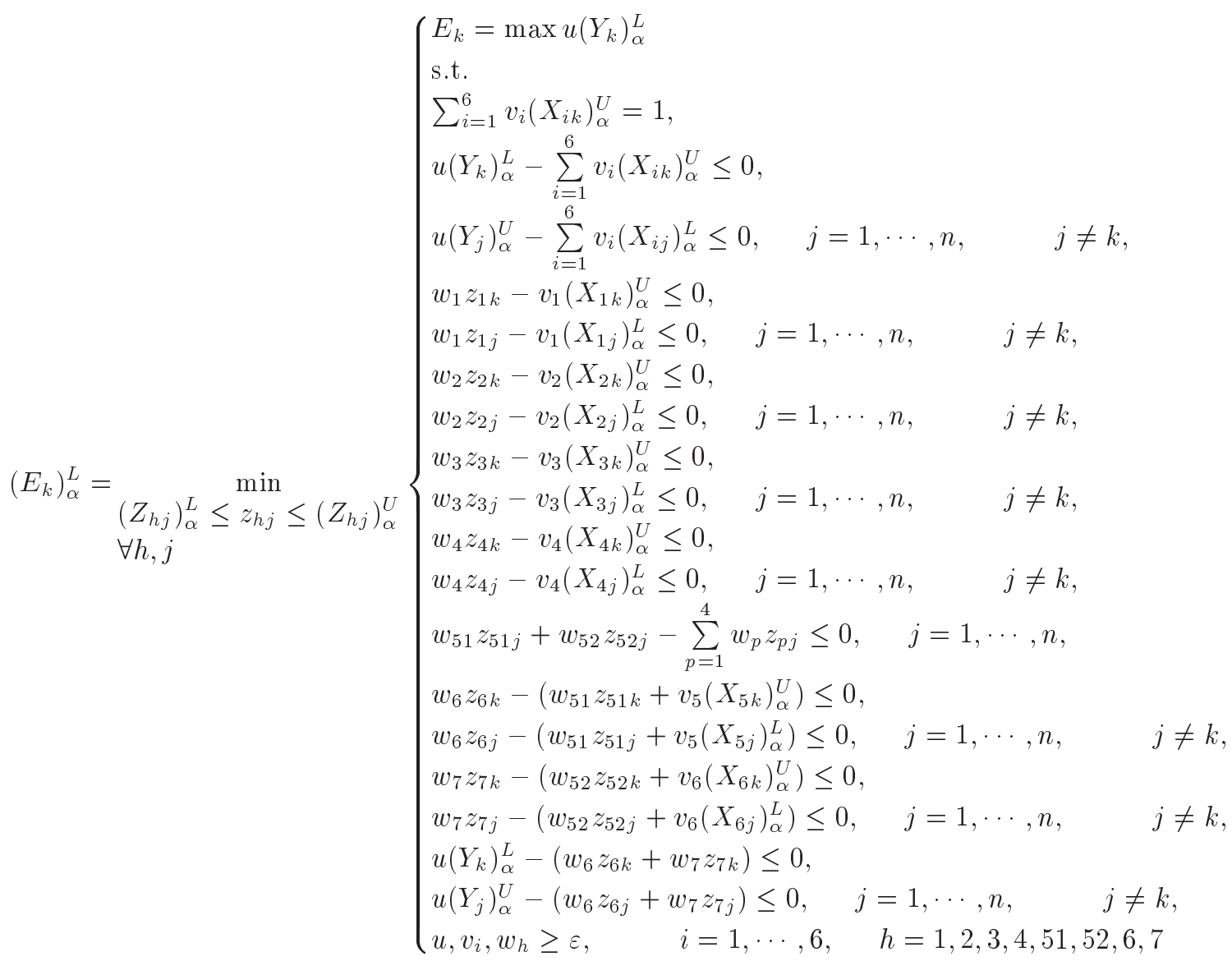

Box II

$$
\begin{aligned}
& \left(Z_{h j}\right)_{\alpha}^{L} \leq z_{h j} \leq\left(Z_{h j}\right)_{\alpha}^{U}, \\
& h=1,2,3,4,51,52,6,7, \quad j=1, \cdots, n, \\
& \alpha_{j}, \lambda_{j}^{(t)}, s_{i}^{x}, s_{h}^{z}, s^{y} \geq 0, \quad i=1, \cdots, 6, \\
& t=1, \cdots, 8, \quad h=1,2,3,4,51,52,6,7, \\
& j=1, \cdots, n .
\end{aligned}
$$

Model (32) is non-linear programming. Therefore, to transform it into linear programming, let:

$$
\begin{aligned}
M_{1 j}=\lambda_{j}^{(1)} z_{1 j}, & M_{2 j}=\lambda_{j}^{(2)} z_{2 j}, \\
M_{3 j}=\lambda_{j}^{(3)} z_{3 j}, & M_{4 j}=\lambda_{j}^{(4)} z_{4 j}, \\
M_{51 j}=\lambda_{j}^{(5)} z_{51 j}, & M_{52 j}=\lambda_{j}^{(5)} z_{52 j}, \\
M_{6 j}=\lambda_{j}^{(6)} z_{6 j}, & M_{7 j}=\lambda_{j}^{(7)} z_{7 j}, \\
j=1, \cdots, n, &
\end{aligned}
$$

$$
\begin{array}{ll}
\hat{M}_{1 j}=\lambda_{j}^{(5)} z_{1 j}, & \hat{M}_{2 j}=\lambda_{j}^{(5)} z_{2 j}, \\
\hat{M}_{3 j}=\lambda_{j}^{(5)} z_{3 j}, & \hat{M}_{4 j}=\lambda_{j}^{(5)} z_{4 j}, \\
\hat{M}_{51 j}=\lambda_{j}^{(6)} z_{51 j}, & \hat{M}_{52 j}=\lambda_{j}^{(7)} z_{52 j}, \\
\hat{M}_{6 j}=\lambda_{j}^{(8)} z_{6 j}, & \hat{M}_{7 j}=\lambda_{j}^{(8)} z_{7 j}, \\
j=1, \cdots, n . &
\end{array}
$$

As seen in Eqs. (33) and (34), $z_{h j}$ has appeared in both $M_{h j}$ and $\hat{M}_{h j}$. $z_{h j}$ varies between lower and upper bounds $\left(\left(Z_{h j}\right)_{\alpha}^{L} \leq z_{h j} \leq\left(Z_{h j}\right)_{\alpha}^{U}\right)$; Therefore, $M_{h j}$ and $\hat{M}_{h j}$ are restricted too. Consider intermediate product $z_{7 j}$ as an example; following Eqs. (33) and (34), $M_{7 j}=$ $\lambda_{j}^{(7)} z_{7 j}$ and $\hat{M}_{7 j}=\lambda_{j}^{(8)} z_{7 j}$; and following Model (15), $\left(Z_{7 j}\right)_{\alpha}^{L} \leq z_{7 j} \leq\left(Z_{7 j}\right)_{\alpha}^{U}$; therefore, $\lambda_{j}^{(7)}\left(Z_{7 j}\right)_{\alpha}^{L} \leq M_{7 j} \leq$ $\lambda_{j}^{(7)}\left(Z_{7 j}\right)_{\alpha}^{U}$ and $\lambda_{j}^{(8)}\left(Z_{7 j}\right)_{\alpha}^{L} \leq \hat{M}_{7 j} \leq \lambda_{j}^{(8)}\left(Z_{7 j}\right)_{\alpha}^{U}$.

By correcting the upper and lower bounds for each $M_{h j}$ and $\hat{M}_{h j}$ and substituting Eqs. (33) and (34) into Model (32), transform it to a linear model as follows: 
$\left(E_{k}\right)_{\alpha}^{L}=\min \theta-\varepsilon\left(\sum_{i=1}^{6} s_{i}^{x}+\sum_{i=1}^{4} s_{i}^{z}+s_{51}^{z}+s_{52}^{z}\right.$

$$
\left.+s_{6}^{z}+s_{7}^{z}+s^{y}\right) \text {, }
$$

s.t.

$$
\begin{aligned}
\theta\left(X_{i k}\right)_{\alpha}^{U} & -\left[\alpha_{k}\left(X_{i k}\right)_{\alpha}^{U}+\sum_{j=1, j \neq k}^{n} \alpha_{j}\left(X_{i j}\right)_{\alpha}^{L}\right] \\
& -\left[\lambda_{k}^{(i)}\left(X_{i k}\right)_{\alpha}^{U}+\sum_{j=1, j \neq k}^{n} \lambda_{j}^{(i)}\left(X_{i j}\right)_{\alpha}^{L}\right] \\
& -s_{i}^{x}=0, \quad i=1,2,3,4,
\end{aligned}
$$$$
\theta\left(X_{5 k}\right)_{\alpha}^{U}-\left[\alpha_{k}\left(X_{5 k}\right)_{\alpha}^{U}+\sum_{j=1, j \neq k}^{n} \alpha_{j}\left(X_{5 j}\right)_{\alpha}^{L}\right]
$$$$
-\left[\lambda_{k}^{(6)}\left(X_{5 k}\right)_{\alpha}^{U}+\sum_{j=1, j \neq k}^{n} \lambda_{j}^{(6)}\left(X_{5 j}\right)_{\alpha}^{L}\right]
$$$$
-s_{5}^{x}=0,
$$$$
\theta\left(X_{6 k}\right)_{\alpha}^{U}-\left[\alpha_{k}\left(X_{6 k}\right)_{\alpha}^{U}+\sum_{j=1, j \neq k}^{n} \alpha_{j}\left(X_{6 j}\right)_{\alpha}^{L}\right]
$$$$
-\left[\lambda_{k}^{(7)}\left(X_{6 k}\right)_{\alpha}^{U}+\sum_{j=1, j \neq k}^{n} \lambda_{j}^{(7)}\left(X_{6 j}\right)_{\alpha}^{L}\right]
$$$$
-s_{6}^{x}=0,
$$$$
\begin{aligned}
& {\left[\alpha_{k}\left(Y_{k}\right)_{\alpha}^{L}+\sum_{j=1, j \neq k}^{n} \alpha_{j}\left(Y_{j}\right)_{\alpha}^{U}\right]} \\
& \quad+\left[\lambda_{k}^{(8)}\left(Y_{k}\right)_{\alpha}^{L}+\sum_{j=1, j \neq k}^{n} \lambda_{j}^{(8)}\left(Y_{j}\right)_{\alpha}^{U}\right]-s^{y}=\left(Y_{k}\right)_{\alpha}^{L},
\end{aligned}
$$$$
\sum_{j=1}^{n} M_{q j}-\sum_{j=1}^{n} \hat{M}_{q j}-s_{q}^{z}=0, \quad q=1, \cdots, 4
$$$$
\sum_{j=1}^{n} M_{51 j}-\sum_{j=1}^{n} \hat{M}_{51 j}-s_{51}^{z}=0
$$$$
\sum_{j=1}^{n} M_{52 j}-\sum_{j=1}^{n} \hat{M}_{52 j}-s_{52}^{z}=0
$$

$$
\begin{aligned}
& \sum_{j=1}^{n} M_{6 j}-\sum_{j=1}^{n} \hat{M}_{6 j}-s_{6}^{z}=0, \\
& \sum_{j=1}^{n} M_{7 j}-\sum_{j=1}^{n} \hat{M}_{7 j}-s_{7}^{z}=0,
\end{aligned}
$$

$$
\begin{gathered}
\lambda_{j}^{(q)}\left(Z_{q j}\right)_{\alpha}^{L} \leq M_{h j} \leq \lambda_{j}^{(q)}\left(Z_{q j}\right)_{\alpha}^{U}, \\
q=1,2,3,4, \quad j=1, \cdots, n, \\
\lambda_{j}^{(5)}\left(Z_{q j}\right)_{\alpha}^{L} \leq \hat{M}_{h j} \leq \lambda_{j}^{(5)}\left(Z_{q j}\right)_{\alpha}^{U}, \\
q=1,2,3,4, \quad j=1, \cdots, n,
\end{gathered}
$$$$
\lambda_{j}^{(5)}\left(Z_{51 j}\right)_{\alpha}^{L} \leq M_{51 j} \leq \lambda_{j}^{(5)}\left(Z_{51 j}\right)_{\alpha}^{U},
$$$$
\lambda_{j}^{(6)}\left(Z_{51 j}\right)_{\alpha}^{L} \leq \hat{M}_{51 j} \leq \lambda_{j}^{(6)}\left(Z_{51 j}\right)_{\alpha}^{U}
$$$$
\lambda_{j}^{(5)}\left(Z_{52 j}\right)_{\alpha}^{L} \leq M_{52 j} \leq \lambda_{j}^{(5)}\left(Z_{52 j}\right)_{\alpha}^{U}
$$$$
\lambda_{j}^{(7)}\left(Z_{52 j}\right)_{\alpha}^{L} \leq \hat{M}_{52 j} \leq \lambda_{j}^{(7)}\left(Z_{52 j}\right)_{\alpha}^{U}
$$$$
\lambda_{j}^{(6)}\left(Z_{6 j}\right)_{\alpha}^{L} \leq M_{6 j} \leq \lambda_{j}^{(6)}\left(Z_{6 j}\right)_{\alpha}^{U},
$$$$
\lambda_{j}^{(8)}\left(Z_{6 j}\right)_{\alpha}^{L} \leq \hat{M}_{6 j} \leq \lambda_{j}^{(8)}\left(Z_{6 j}\right)_{\alpha}^{U},
$$$$
\lambda_{j}^{(7)}\left(Z_{7 j}\right)_{\alpha}^{L} \leq M_{7 j} \leq \lambda_{j}^{(7)}\left(Z_{7 j}\right)_{\alpha}^{U},
$$$$
\lambda_{j}^{(8)}\left(Z_{7 j}\right)_{\alpha}^{L} \leq \hat{M}_{7 j} \leq \lambda_{j}^{(8)}\left(Z_{7 j}\right)_{\alpha}^{U},
$$$$
\alpha_{j}, \lambda_{j}^{(t)}, s_{i}^{x}, s_{h}^{z}, s^{y} \geq 0, \quad i=1, \cdots, 6,
$$$$
t=1, \cdots 8, \quad h=1,2,3,4,51,52,6,7,
$$

$$
j=1, \cdots, n \text {. }
$$

The optimal values for $M_{h j}, \hat{M}_{h j}$, and $\lambda_{j}^{(t)}$ are obtained by Model (35). The optimal value of $z_{h j}^{*}$ is achieved by substituting this parameter into Models (33) and (34). After solving Model (35), the optimal values of reduced costs of $s_{i}^{x}, s_{h}^{z}$, and $s^{y}$ are the values of multipliers $v_{i}^{*}$, $w_{h}^{*}$, and $u^{*}$, respectively. Therefore, the efficiencies of 
processes are as follows:

$$
\begin{aligned}
\left(E_{k}^{1}\right)_{\alpha}^{L}= & w_{1}^{*} z_{1 k}^{*} / v_{1}^{*}\left(X_{1 k}\right)_{\alpha}^{U}, \\
\left(E_{k}^{2}\right)_{\alpha}^{L}= & w_{2}^{*} z_{2 k}^{*} / v_{2}^{*}\left(X_{2 k}\right)_{\alpha}^{U}, \\
\left(E_{k}^{3}\right)_{\alpha}^{L}= & w_{3}^{*} z_{3 k}^{*} / v_{3}^{*}\left(X_{3 k}\right)_{\alpha}^{U}, \\
\left(E_{k}^{4}\right)_{\alpha}^{L}= & w_{4}^{*} z_{4 k}^{*} / v_{4}^{*}\left(X_{4 k}\right)_{\alpha}^{U}, \\
\left(E_{k}^{5}\right)_{\alpha}^{L}= & \left(w_{51}^{*} z_{51 k}^{*}+w_{52}^{*} z_{52 k}^{*}\right) \\
& /\left(w_{1}^{*} z_{1 k}^{*}+w_{2}^{*} z_{2 k}^{*}+w_{3}^{*} z_{3 k}^{*}+w_{4}^{*} z_{4 k}^{*}\right), \\
\left(E_{k}^{6}\right)_{\alpha}^{L}= & w_{6}^{*} z_{6 k}^{*} /\left(w_{51}^{*} z_{51 k}^{*}+v_{5}^{*}\left(X_{5 k}\right)_{\alpha}^{U}\right), \\
\left(E_{k}^{7}\right)_{\alpha}^{L}= & w_{7}^{*} z_{7 k}^{*} /\left(w_{52}^{*} z_{51 k}^{*}+v_{6}^{*}\left(X_{6 k}\right)_{\alpha}^{U}\right), \\
\left(E_{k}^{8}\right)_{\alpha}^{L}= & \left(u^{*}\left(Y_{k}\right)_{\alpha}^{L}\right) /\left(w_{6}^{*} z_{6 k}^{*}+w_{7}^{*} z_{7 k}^{*}\right) .
\end{aligned}
$$

\section{Case study}

The network supply chain of a shipping company has been chosen as case study. Considering that about $90 \%$ of the world trade is transported by sea, the importance of shipping industry in the international trade as 3PL has been duly recognized in many academic institutions. However, probably less attention has so far been given to the network supply chains in this industry by themselves as the core subject for research and studies. It is well known that shipping movements are conducted from port to port and country to country and multi-nationally. There exists a vast and assorted network of vendors and beneficiaries, earnings and expenditures, interconnected from various places of the world, consisting of numerous members, elements, currencies, etc. Ships have a large number of users and beneficiaries in various locations; they are repaired in one port of the world and supplied in other ports, and may make their earnings in third places, which may be very far from any of the above-mentioned locations. Henceforth, for our case study, the supply chain network of a leading shipping company in Iran is reviewed, which is shown in Figure 3.

Detailed studies have been carried out on the network supply chain of the subject company, which is drawn in the given diagram. It is understood that there are three major activities in this business. The first major activity (supplying) consists of providing a ship as a basic tool and means to efficiently conduct the business, and maintaining her in running and available condition all the while. The second major activity (production) in our diagram and work flow is chartering her out on the daily cost basis (time charter) as output of this activity for the commercial department, which utilize the ship and make their earning by producing shipping services. The third major activity (distribution) is the actions and conducts of distributors, forwarders, and selling agents (similar to selling agents of airlines) who sell the service to end users locally and internationally.

\subsection{Major Activity I: supplying}

The first sub-process in this activity is the provision of technical repairs. There are two categories of repairs:

1. Voyage repairs, which are a type of continuous repair of the ship as she is running;

2. Dry docks repairs, which are required by Statute. Vessels must be taken to dry docks and complete

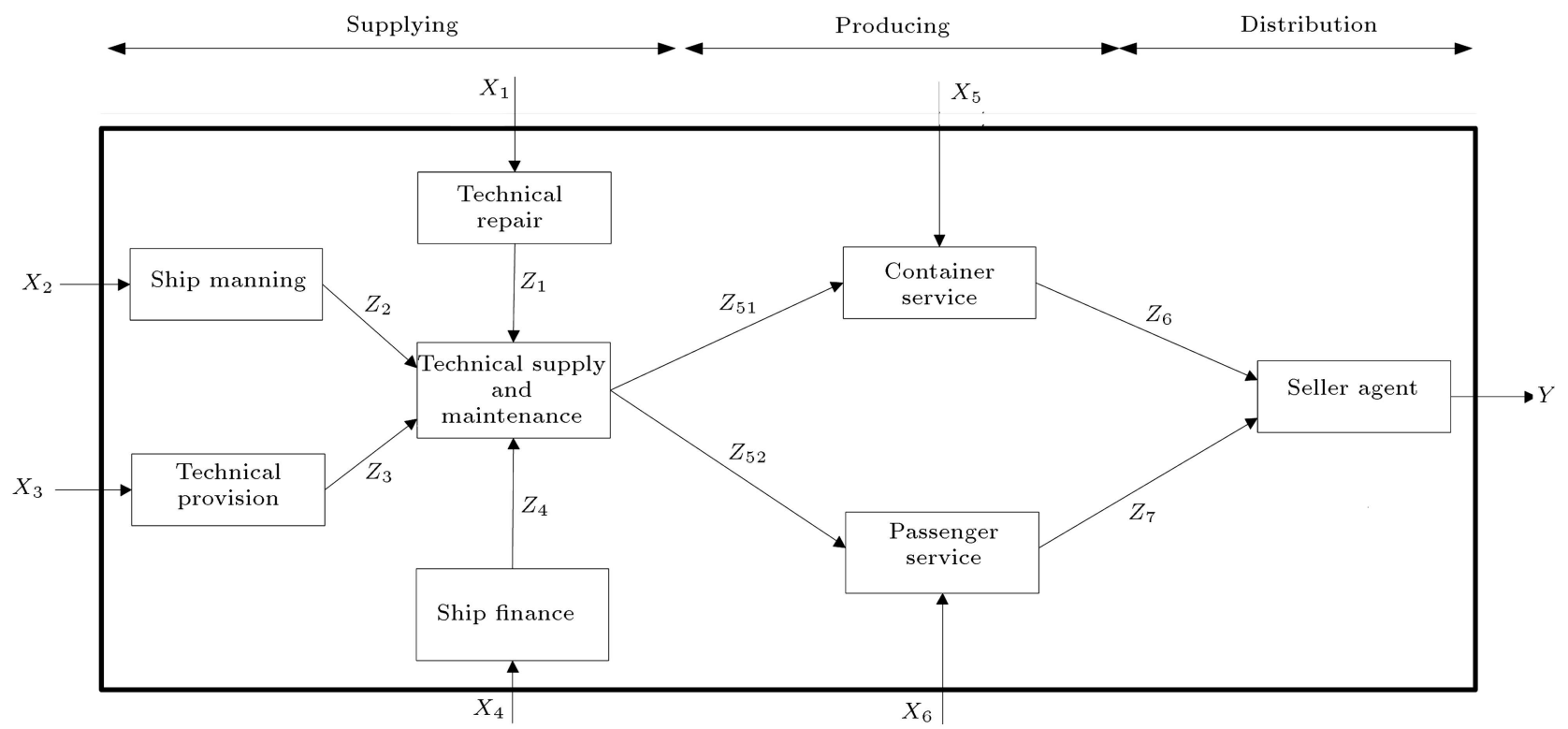

Figure 3. Supply chain network of the shipping line in Iran. 
inspection of ship bottom, sea chests, and underwater area must be effected to ensure that the vessel is fully safe for her assignments.

Naturally, the voyage and dry docking repairs must be performed as fast as possible to minimize off-hire period and to ensure that the vessel is kept on operational and available condition to the maximum possible. The number of operational days out of every 365 days of the year can be taken as the output of this activity to measure the efficiency of this sub-process.

The next sub-process is ship manning, whose function is to man and run the ship. There are 304 marine employees in the company in terms of officers and crew, out of which 61 persons are permanent employees and the rest of 243 hands are supplied by at least three ships manning companies in line with the company's policy of outsourcing. The manning contract is based on cost-plus and payment of a fixed premium on top of their actual payments and basic salary. Therefore, the input of this sub-process is what they pay to their employed officers and crew and the output of this sub-process is the remuneration they get from the main company in addition to their paid salaries. The company has adopted outsourcing policy instead of permanent employment.

The following sub-process is technical supplies and provisions, which is responsible to supply spare parts, lubricating oil, fresh water, paints, chemicals, buying insurance, statutory surveys, stores for a given voyage, etc. The company normally pays $3 \%$ overhead costs on top of the actual purchasing price of the subject services.

The fourth sub-process of this activity is financing whose function is to provide and deliver a suitable bareboat ship. The initial capital and profit of $7 \%$ per annum is recovered through three monthly installments and depreciated annually in a form of lease and purchase. The input of this sub-process is the initial capital acquired and the output is the periodical depreciation of received loan.

To elaborate on the function of ship technical supply and maintenance activity, we have to consider that all the above sub-processes are performed in order for this department to maintain the ship in running condition and supply her to commercial department in the form of time charter. This section must cover all its costs described in the four sub-processes above by collecting daily charter rate from commercial department. Therefore, the input of this activity is the sum of all costs described per above sub-processes and output is the daily time charter rate collected for supplying the ship in running condition to commercial department.

\subsection{Major Activity II: producing}

At this activity, the vessel is taken over in an available condition by technical department on a time charter basis. There are two activities of service production in the company:

1. Passenger and car carriage, which is affected by Catamaran High Speed Crafts and RORO (Roll On-Roll Off) ships;

2. Container carriage, which is mainly feeder carriage in the regions of Persian Gulf, Oman Sea, and north of Indian Ocean.

At this activity, the vessel is allocated a commercial route in form of a specific voyage instruction and a shipping service is produced, which is offered to the market (distributors described in the next stage). Various commercial operation costs such as fuel and bunker costs, port dues, cargo operation costs, container costs, P\&I (Protection and Indemnity) club costs, and passenger meals as well as other operational and non-operational costs including tax and other probable financial costs are added to the vessel's daily time charter hire costs taken from the first activity, and relevant shipping service is produced. The output of this activity will be the numbers of containers, passengers, and cars carried against the input, which is the sum of all costs described above.

\subsection{Major Activity III: distribution}

The service is sold to customers and end users by sales staff, forwarders, sales offices, and agents located in the various parts of the world. The revenue is generated and the output of this section is the net income after deducting all the above-mentioned costs.

\subsection{Data and results}

The data have been extracted from the operational reports of a shipping company in Iran. They consist of year-end results for 4 consecutive years, i.e. year 2008-2009 up to year 2011-2012. The fiscal year for this company is 365 days, commencing on March 21st, which is Iranian New Year. Therefore, each fiscal year involves two Gregorian-calendar years, i.e. from March 21st of every Gregorian year to March 20th of the following year. It may be mentioned that as we could not access the database of another similar shipping line, in this paper, there are four DMUs of a single shipping line in which each DMU refers to one fiscal year of the same company.

Table 1 shows the inputs, intermediate products, and outputs of the shipping company in Iran for four fiscal years. Note that the years in Table 1 are actually represented by their commencing dates, e.g. the fiscal year 2008-2009 has been denoted by 2008 for simplicity in writing.

By applying Models (29), (30), (35), and (36), the upper and lower bounds of the $\alpha$-cut of the fuzzy supply chain and 8 sub-processes are calculated. Table 2 shows 
Table 1. Triangular fuzzy numbers for 4 years of the shipping line in Iran.

\begin{tabular}{|c|c|c|c|c|}
\hline Indicator & Year 2008 & Year 2009 & Year 2010 & Year 2011 \\
\hline $\begin{array}{l}\text { Costs of repairs (voyage } \\
+ \text { dry dock) }\left(X_{1}\right)\end{array}$ & $(234.92,264.92,294.92)$ & $(202.97,232.97,262.97)$ & $(134.7,164.7,194.7)$ & $(175.14,205.14,235.14)$ \\
\hline Crew cost $\left(X_{2}\right)$ & $(504.28,534.28,564.28)$ & $(662.14,692.14,722.14)$ & $(705.61,735.61,765.61)$ & $(824.67,854.67,884.67)$ \\
\hline $\begin{array}{l}\text { Costs of spare parts, } \\
\text { provisions, insurance, } \\
\text { etc. }\left(X_{3}\right)\end{array}$ & $(183.95,213.95,243.95)$ & $(302.76,332.76,362.76)$ & $(291.43,321.43,351.43)$ & $(325.74,355.74,385.74)$ \\
\hline Ship purchase cost $\left(X_{4}\right)$ & $(11909,11909,11909)$ & $(11503,11503,11503)$ & $(10194,10194,10194)$ & $(9605,9605,9605)$ \\
\hline $\begin{array}{l}\text { Commercial container } \\
\text { operation cost }+ \text { other } \\
\text { costs }\left(X_{5}\right)\end{array}$ & $(2218.1,2248.1,2278.1)$ & $(1835.77,1865.77,1895.77)$ & $(2076.59,2106.59,2136.59)$ & $(1571.41,1601.41,1631.41)$ \\
\hline $\begin{array}{l}\text { Commercial passenger } \\
\text { operation cost }+ \text { other } \\
\text { costs }\left(X_{6}\right)\end{array}$ & $(200.97,230.97,260.97)$ & $(246.91,276.91,306.91)$ & $(283.33,313.33,343.33)$ & $(336.85,366.85,396.85)$ \\
\hline $\begin{array}{l}\text { Lease }+ \text { purchasing } \\
\text { (by installments) }\left(Z_{1}\right)\end{array}$ & $(376.02,406.02,436.02)$ & $(1149.13,1179.13,1209.13)$ & $(519.17,549.17,579.17)$ & $(536.19,566.19,596.19)$ \\
\hline Ship manning cost $\left(Z_{2}\right)$ & $(525.65,555.65,585.65)$ & $(689.82,719.82,749.82)$ & $(735.04,765.04,795.04)$ & $(858.86,888.86,918.86)$ \\
\hline $\begin{array}{l}\text { Supply of spares \& } \\
\text { provisions plus } \\
\% 3 \text { overhead }\left(Z_{3}\right)\end{array}$ & $(190.37,220.37,250.37)$ & $(312.74,342.74,372.74)$ & $(301.08,331.08,361.08)$ & $(336.41,366.41,396.41)$ \\
\hline $\begin{array}{l}\text { Total available days per } \\
\text { year (on-hire days) }\left(Z_{4}\right)\end{array}$ & $(3,3.15,3.31)$ & $(3.91,4.06,4.22)$ & $(3.99,4.15,4.3)$ & $(4.32,4.47,4.63)$ \\
\hline $\begin{array}{l}\text { Time charter to service } \\
\text { provider (container) }\left(Z_{51}\right)\end{array}$ & $(695.7,725.7,755.7)$ & $(1777.54,1807.54,1837.54)$ & $(1265.5,1295.5,1325.5)$ & $(1443.16,1473.16,1503.16)$ \\
\hline $\begin{array}{l}\text { Time charter to service } \\
\text { provider (passenger) }\left(Z_{52}\right)\end{array}$ & $(716.04,746.04,776.04)$ & $(588.18,618.18,648.18)$ & $(520.41,550.41,580.41)$ & $(731.33,761.33,791.33)$ \\
\hline $\begin{array}{l}\text { No. of containers } \\
\text { carried per year }\left(Z_{6}\right)\end{array}$ & $(193,193.93,194.86)$ & $(339.86,340.79,341.72)$ & $(304.54,305.47,306.4)$ & $(328.56,329.49,330.42)$ \\
\hline $\begin{array}{l}\text { No. of passengers }+ \text { cars } \\
\text { carried per year }\left(Z_{7}\right)\end{array}$ & $(152.08,153.01,153.94)$ & $(291.99,292.92,293.85)$ & $(296.27,297.19,298.12)$ & $(346.06,346.99,347.92)$ \\
\hline Net income (profits) $(Y)$ & $(676.1,706.1,736.1)$ & $(43.74,73.74,103.74)$ & $(1003.1,1033.1,1063.1)$ & $(397.61,427.61,457.61)$ \\
\hline
\end{tabular}




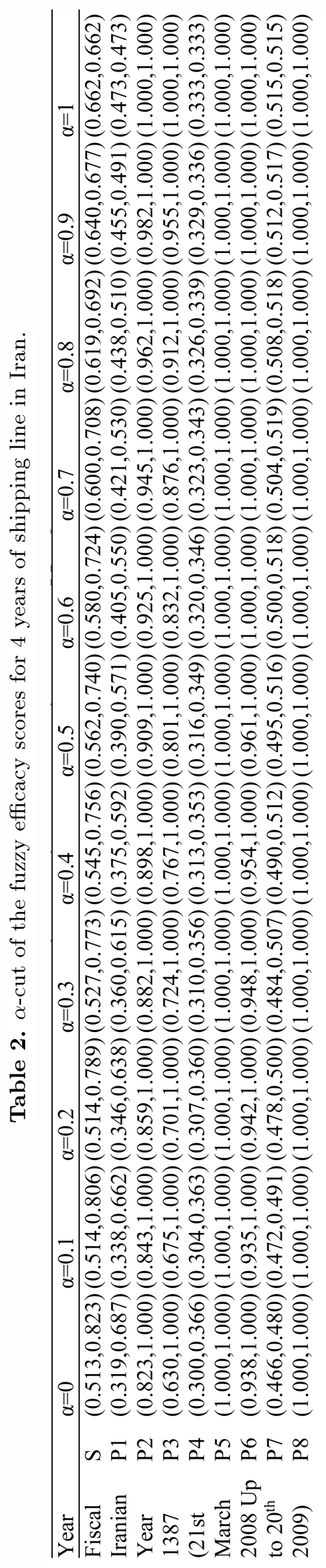

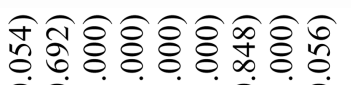
$0 .-1-1.0$

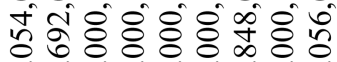

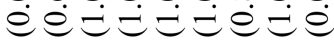

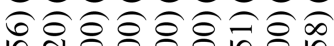

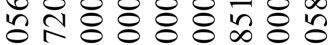
$\circ 0-\dot{i} \dot{0} \dot{0}$

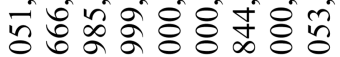

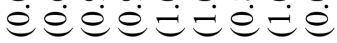

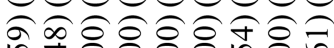

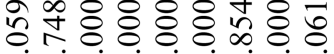
$\circ 0$ - $-\dot{-} 0$ 考守 ée $\dot{e}=\dot{e}=\dot{e}$

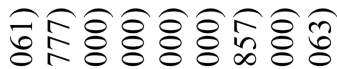
$\circ 0$ - $\dot{0} 0 \dot{0}$ पै $\ddot{\theta} \dot{e} \dot{\theta} \dot{0}=\dot{0} \dot{0}=\dot{0}$

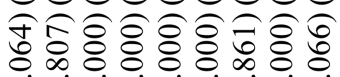
0 : $-i-i 0-\dot{0}$

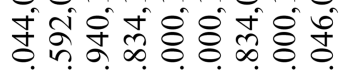

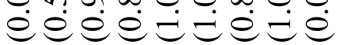

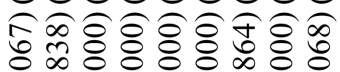
$00-1-\dot{0} 0$

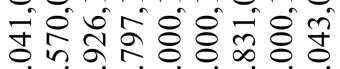

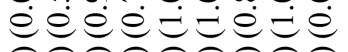

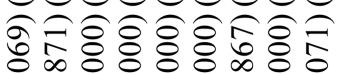
$\dot{0} \dot{0}-1-\dot{-} \dot{0}-\dot{0}$ की

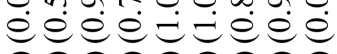

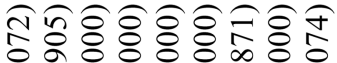
$00-\dot{0}-\dot{0}-\dot{0}$ กิ é $\dot{0} \dot{0}=\dot{j} \dot{0} \dot{0}$

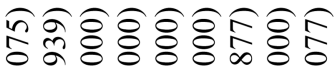
0 - $-1-i-1$ लำ

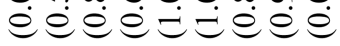

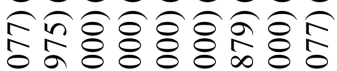
0.0

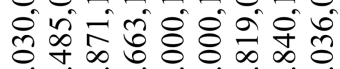

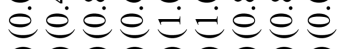

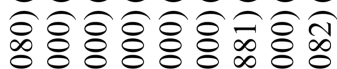
0 - $-\dot{-} 0$ की $\dot{e} \dot{e} \dot{e} \dot{e}=\dot{e} \dot{e} \dot{e}$

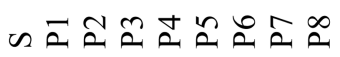

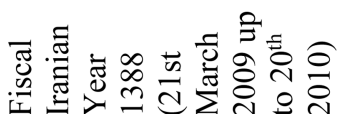

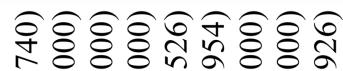
1. की 80 i 过 $\doteq \dot{0}=\dot{=}$

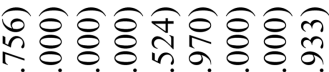
$0-\dot{-}-\dot{0}-\dot{0}$

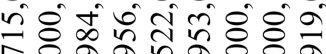
$\dot{e} \doteq \dot{e} \dot{e} \dot{e} \dot{e} \doteq \dot{e}$

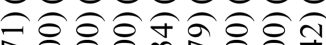
굥ㅇㅇㅇㅡ. 0 - $-i 00$ - 0

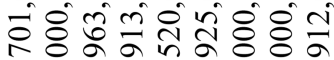

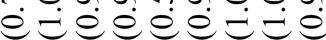
응ㅎํ스응

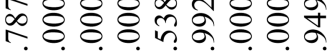
0 -

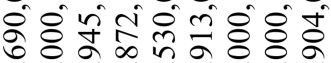

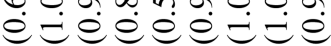

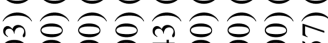

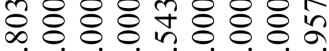
$0-\dot{-}-\dot{-}-\dot{0}$

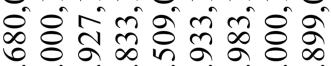

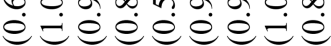

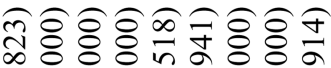
$\dot{0}-\dot{-} 0 \dot{0}-\dot{0}$

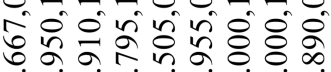

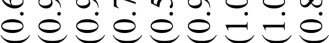
ชิวิ)  0 - $-\dot{0}-\dot{0}$

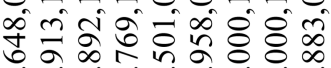

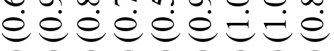

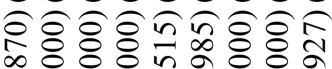
$0-1-0$

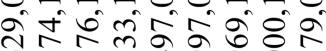

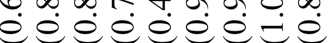

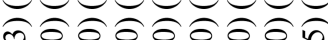

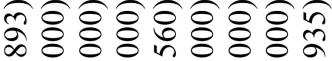

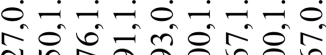
సิํํ유. $\dot{e} \dot{e} \dot{e} \dot{e}=\dot{e}=\dot{e}$

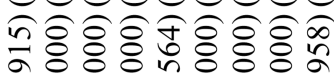
$0-1-0-1-i 0$

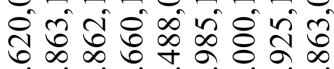
$\dot{e} \dot{e} \dot{e} \dot{e} \dot{e}=\dot{e}$

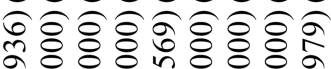
+0

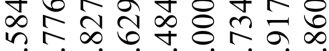
é巳é巳e $\dot{e} \dot{e} \dot{e}$

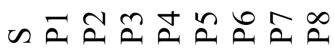

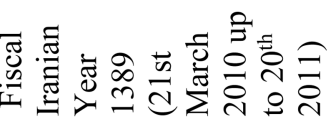

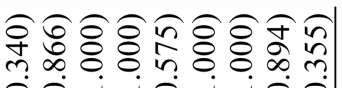
0 0 Ð $\dot{e} \doteq \dot{e}=\dot{\theta}=\dot{e}$

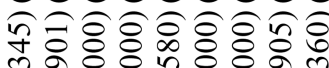
m ๗ิ กิ

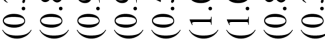

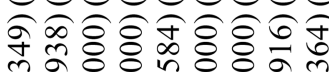

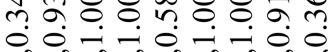

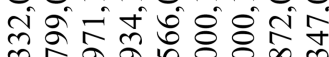

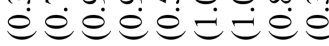

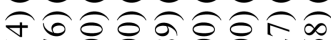
๓ 0 0 $\dot{0}_{0}$ i ㅅํำ

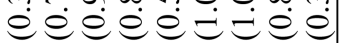

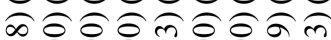

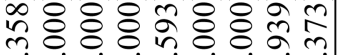
0 กิ

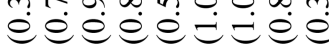
앙ㅇㅇㅇㅇㅇㅇㅇำ

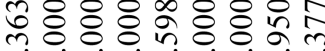
o - $-\dot{-i} 0$ - $-\dot{0} 0$

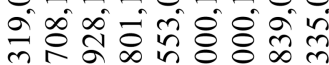

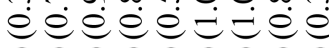

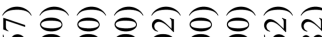
6 ind 0.0 m

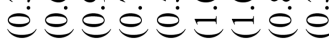

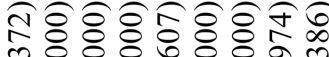
$30-1$

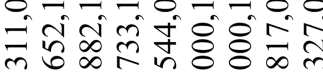

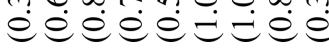

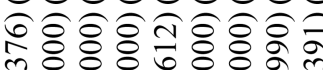
of

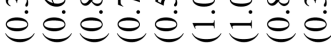

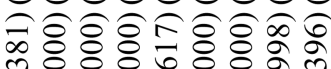

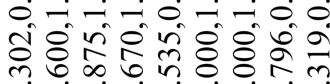

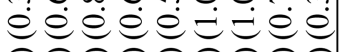

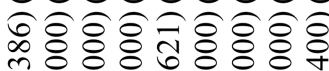
0 - - - 0 - - - 0 कूर

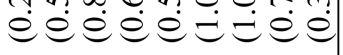

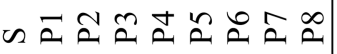

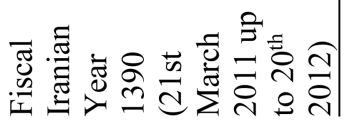


the result for $\alpha=0,0.1, \cdots, 1$ for supply chain and subprocesses, where S, P1, P2, P3, P4, P5, P6, P7, and $\mathrm{P} 8$ refer to supply chain of the shipping company, ship finance, ship manning, technical provision, technical repairs, technical supply \& maintenance, container service, passenger service, and selling agent.

In each $\alpha$-cut, the lowest and highest efficiency scores for supply chain and members are calculated. The most likely cases of $\alpha=1$ and $\alpha=0$ are worth further discussion. At $\alpha=1$, there is only one value. At $\alpha=0$, the upper and lower efficiency scores are shown. For example, at $\alpha=1$, the supply chain efficiency for year 2008 is 0.662 while at $\alpha=0$, this value varies between 0.513 and 0.823 .

Among all years of the shipping company, no year has efficiency of one. For example, in the most likely case, this value varies from 0.054 (DMU 2009) to 0.740 (DMU 2010); at $\alpha=0$, the upper and lower efficiencies vary from 0.08 (DMU 2009) to 0.936 (DMU 2010) and 0.028 (DMU 2009) to 0.584 (DMU 2010), respectively. The supply chain for year 2010 has the highest efficiency at $\alpha=1\left(E_{k}=0.740\right)$.

Ship manning (P2) and technical provision (P3) show efficiency values of one in all the years (2008 up to 2010) in the most likely case of $\alpha=1$, while, when research quality is represented by fuzzy numbers, no years have full efficiencies.

\section{Conclusion}

The supply chain is composed of a network of associated and interdependent links and organizations reciprocally and co-operatively working to achieve the highest efficiency. It is proven that, in order to achieve the highest efficiency in each network, all the relevant processes and sub-processes must have the highest efficiency. It necessitates intelligent and systematic evaluation and monitoring of network and all the members associated. Kao and Hwang [7] developed a relational network DEA model for calculating the efficiency of the network system. The model calculated the efficiency of system and processes using a mathematical program. Therefore, the relational network DEA model is found to be a suitable mathematically defined method for evaluating a supply chain.

However, the existing relational network DEA models evaluate the performance of decision making units with precise data. Whereas, in the real-world applications, there are many supply chain networks with imprecise and vague figures. This paper extends relational network DEA from the deterministic environment with exact figures to fuzzy fields, where there are imprecise data represented by fuzzy numbers.

A pair of two-level mathematical programs was utilized to convert the fuzzy relational network DEA to a conventional crisp method. For this purpose, in each $\alpha$-cut, the upper and lower bounds of the efficiencies for supply chain and members were calculated. The idea was to convert the two-level mathematical programs into one-level ones for calculating the upper and lower bounds. The conversion of the lower bound into onelevel program is not as straightforward as converting the upper bound, because the directions of the inner program and other programs in lower bound are different. Thus, the duality theorem was used to change the direction of the inner program.

Fuzzy efficiency measurements are more informative than crisp methods, because they provide not only the most likely values, but also the range that all possible values can appear inside it. This prevents the decision maker from being over-confident with results that are not 100 percent correct and making inappropriate decisions.

In this paper, the proposed model was employed by some actual data from the supply chain of a shipping company in Iran. The result showed that the supply chain in none of the four consecutive years had perfect efficiency. For example, at $\alpha=1$, the efficiency of company varied between 0.053 and 0.740 .

\section{References}

1. Consulting, D., Energizing the Supply Chain: Trends and Issues in Supply Chain Management, New York, NY (1999).

2. Xiao, T. and Yang, D. "Price and service competition of supply chains with risk-averse retailers under demand uncertainty", Int. J. Prod. Econ., 114(1), pp. 187-200 (2008).

3. Bhaskar, V. and Lallement, P. "Modeling a supply chain using a network of queues", Appl. Math. Model., 34(8), pp. 2074-2088 (2010).

4. Ross, A. and Droge, C. "An integrated benchmarking approach to distribution center performance using DEA modeling", J. of Oper. Man., 20(1), pp. 19-32 (2002).

5. Easton, L., Murphy, D.J. and Pearson, J.N. "Purchasing performance evaluation: with data envelopment analysis", Eur. J. of Purch. \& Supply Man., 8(3), pp. 123-134 (2002).

6. Talluri, S., Narasimhan, R., and Nair, A. "Vendor performance with supply risk: A chance-constrained DEA approach", Int. J. Prod. Econ., 100(2,) pp. 212222 (2006).

7. Kao, C. and Hwang, S.-N. "Efficiency measurement for network systems: IT impact on firm performance", Decis. Support Syst., 48(3), pp. 437-446 (2010).

8. Kao, C. and Liu, S.-T. "Efficiencies of two-stage systems with fuzzy data", Fuzzy Set Syst., 176(1), pp. 20-35 (2011).

9. Kao, C. and Lin, P.-H. "Efficiency of parallel production systems with fuzzy data", Fuzzy Set Syst., 198(0), pp. 83-98 (2012). 
10. Charnes, A., Cooper, W.W., and Rhodes, E. "Measuring the efficiency of decision making units", Eur. J. Oper. Res., 2(6), pp. 429-444 (1978).

11. Lewis, H.F. and Sexton, T.R. "Network DEA: efficiency analysis of organizations with complex internal structure", Comput. Oper. Res., 31(9), pp. 1365-1410 (2004).

12. Seiford, L.M. and Zhu, J. "Profitability and marketability of the top 55 U.S. commercial banks", Man. Sci., 45(9) pp. 1270-1288 (1999).

13. Sexton, T. and Lewis, H. "Two-Stage DEA: An application to major league baseball", J. Prod. Anal., 19(2-3), pp. 227-249 (2003).

14. Zhu, J. "Multi-factor performance measure model with an application to Fortune 500 companies", Eur. J. Oper. Res., 123(1), pp. 105-124 (2000).

15. Färe, R. and Grosskopf, S. "Network DEA", Socio. Econ. Plann. Sci., 34(1), pp. 35-49 (2000).

16. Kao, C. and Hwang, S.-N. "Efficiency decomposition in two-stage data envelopment analysis: An application to non-life insurance companies in Taiwan", Eur. J. Oper. Res., 185(1), pp. 418-429 (2008).

17. Kao, C. "Efficiency decomposition in network data envelopment analysis: A relational model", Eur. J. Oper. Res., $192(3)$, pp. 949-962 (2009).

18. Kao, C. "Dynamic data envelopment analysis: A relational analysis", Eur. J. Oper. Res., 227(2), pp. 325-330 (2013).

19. Guan, J. and Chen, K. "Measuring the innovation production process: A cross-region empirical study of China's high-tech innovations", Technovation, 30(5), pp. 348-358 (2010).

20. Yang, C. and Liu, H.-M. "Managerial efficiency in Taiwan bank branches: A network DEA", Econ. Model., 29(2), pp. 450-461 (2012).

21. Hsieh, L.-F. and Lin, L.-H. "A performance evaluation model for international tourist hotels in Taiwan-An application of the relational network DEA", Int. J. Hosp. Manag., 29(1), pp. 14-24 (2010).

22. Chen, C. and Yan, H. "Network DEA model for supply chain performance evaluation", Eur. J. Oper. Res., 213(1), pp. 147-155 (2011).

23. Toloo, M., Emrouznejad, A., and Moreno, P. "A linear relational DEA model to evaluate two-stage processes with shared inputs", J. Comput. Appl. Math., pp. 1-17 (2015).

24. Hatami-Marbini, A., Emrouznejad, A., and Tavana, M. "A taxonomy and review of the fuzzy data envelopment analysis literature: Two decades in the making", Eur. J. Oper. Res., 214(3), pp. 457-472 (2011).

25. Zadeh, L.A. "Fuzzy sets", Inf. Control, 8(3), pp. 338353 (1965).

26. Karsak, E.E. "Using data envelopment analysis for evaluating flexible manufacturing systems in the presence of imprecise data", Int. J. Adv. Manuf. Tech., 35(9-10), pp. 867-874 (2008).
27. Sengupta, J.K. "A fuzzy systems approach in data envelopment analysis", Comput. Math. Appl., 24(8-9), pp. 259-266 (1992).

28. Triantis, K. and Girod, O. "A mathematical programming approach for measuring technical efficiency in a fuzzy environment", J. Prod. Anal., 10(1), pp. 85-102 (1998).

29. Chiang, T.-A. and Che, Z.H. "A fuzzy robust evaluation model for selecting and ranking NPD projects using Bayesian belief network and weight-restricted DEA", Expert Syst. Appl., 37(11), pp. 7408-7418 (2010).

30. Azadeh, A. and Alem, S.M. "A flexible deterministic, stochastic and fuzzy Data Envelopment Analysis approach for supply chain risk and vendor selection problem: Simulation analysis", Expert Syst. Appl., 37(12), pp. 7438-7448 (2010).

31. Juan, Y.-K. "A hybrid approach using data envelopment analysis and case-based reasoning for housing refurbishment contractors selection and performance improvement", Expert Syst. Appl., 36(3, Part 1), pp. 5702-5710 (2009).

32. Bagherzadeh Valami, H. "Cost efficiency with triangular fuzzy number input prices: An application of DEA", Chaos Soliton Fract., 42(3), pp. 1631-1637 (2009).

33. Wen, M. and Li, H. "Fuzzy data envelopment analysis (DEA): Model and ranking method", J. Comput. Appl. Math., 223(2), pp. 872-878 (2009).

34. Wen, M., You, C., and Kang, R. "A new ranking method to fuzzy data envelopment analysis", Com. Math. Appli., 59(11), pp. 3398-3404 (2010).

35. Lozano, S. and Moreno, P. "Network fuzzy data envelopment analysis", Per. Measur. Fuzzy Data Envelop. Anal., Springer, pp. 207-230 (2014).

36. Jitsuzumi, T. and Nakamura, A. "Causes of inefficiency in Japanese railways: Application of DEA for managers and policymakers", Socio. Econ. Plann. Sci., 44(3), pp. 161-173 (2010).

37. Azadeh, A., Ghaderi, S.F., and Izadbakhsh, H. "Integration of DEA and AHP with computer simulation for railway system improvement and optimization", Appl. Math. Com., 195(2), pp. 775-785 (2008).

38. Scheraga, C.A. "Operational efficiency versus financial mobility in the global airline industry: a data envelopment and Tobit analysis", Transportation Research Part A Policy and Practice, 38(5), pp. 383-404 (2004).

39. Sampaio, B.R., Neto, O.L., and Sampaio, Y. "Efficiency analysis of public transport systems: Lessons for institutional planning", Transportation Research Part A Policy and Practice, 42(3), pp. 445-454 (2008).

40. Martín, J.C. and Román, C. "An application of DEA to measure the efficiency of Spanish airports prior to privatization", J. Air Transp. Manag., 7(3), pp. 149157 (2001). 
41. Cullinane, K., Wang, T.-F., Song, D.-W., and Ji, P. "The technical efficiency of container ports: Comparing data envelopment analysis and stochastic frontier analysis", Transportation Research Part A Policy and Practice, 40(4), pp. 354-374 (2006).

42. Hung, S.-W., Lu, W.-M., and Wang, T.-P. "Benchmarking the operating efficiency of Asia container ports", Eur. J. Oper. Res., 203(3), pp. 706-713 (2010).

43. Markovits-Somogyi, R. "Measuring efficiency in transport: the state of the art of applying data envelopment analysis", Transport, 26(1), pp. 11-19 (2011).

44. Bang, H.-S., Kang, H.-W., Martin, J., and Woo, S.H. "The impact of operational and strategic management on liner shipping efficiency: a two-stage DEA approach", Marit. Policy Manag., 39(7), pp. 653-672 (2012).

45. Panayides, P.M., Lambertides, N., and Savva, C.S. "The relative efficiency of shipping companies", Transport Res. E. Log., 47(5), pp. 681-694 (2011).

46. Charnes, A. and Cooper, W.W. "The non-archimedean CCR ratio for efficiency analysis: A rejoinder to Boyd and Färe", Eur. J. Oper. Res., 15(3), pp. 333-334 (1984).

47. Zadeh, L.A. "Fuzzy sets as a basis for a theory of possibility", Fuzzy Set. Syst., 1(1), pp. 3-28 (1978).

\section{Biographies}

Hashem Omrani is an Assistant Professor of Industrial Engineering at Urmia University of Technology. He received his BSc degree in Bio-Electrical Engineering from Sahand University of Technology, MSc degree in Industrial Engineering from University of Tehran, and $\mathrm{PhD}$ degree in Industrial Engineering from Iran University of Science and Technology (IUST). He has participated in writing a number of papers published in refereed journals and conference proceedings in the Industrial Engineering field. His research interests include linear and non-linear optimization, multiple criteria decision making, supply chain management, efficiency and productivity analysis, uncertain programming, game theory, and econometrics.

Mehdi Keshavarz is a $\mathrm{PhD}$ candidate at University of Tehran. He received BSc and MSc degrees in Industrial Engineering from Urmia University of Technology. He has several papers in refereed journals and conference proceedings. His research interest includes efficiency analysis, operation research, supply chain, and location problems.

Seyed Farid Ghaderi is a Professor of Industrial Engineering at University of Tehran. He received his BSc degree in Electrical Engineering from Ferdowsi University of Mashhad, MSc degree in Industrial Engineering from Amirkabir University of Technology, and $\mathrm{PhD}$ degree in Industrial Engineering from Tokyo University of Technology. He has participated in writing a number of papers published in refereed journals and conference proceedings in the industrial engineering field. His research interests include energy, supply chain management, efficiency and productivity analysis, fuzzy programming, and econometrics. 